Key Words:

XAFS

Zeolites

Sodalite

Clarkeite

Retention:

Permanent

\title{
Characterization of Uranium in Archived 2H Evaporator Scale
}

\author{
Martine C. Duff, Douglas B. Hunter, William R. Wilmarth \\ and Arthur Jurgensen
}

\section{REPORT DATE: FEBRUARY 24, 2004}

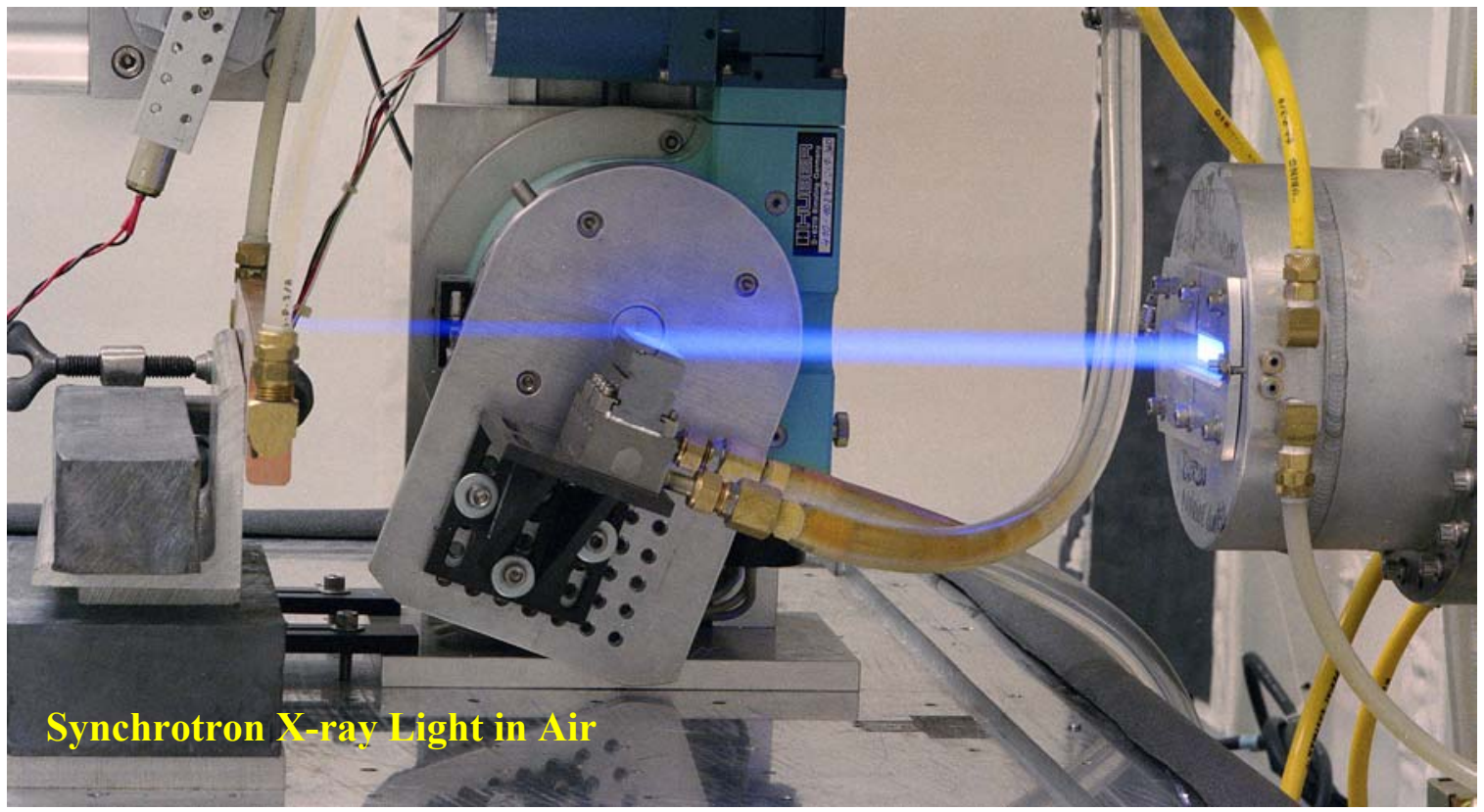

Westinghouse Savannah River Company

Savannah River Site

Aiken, SC 29808

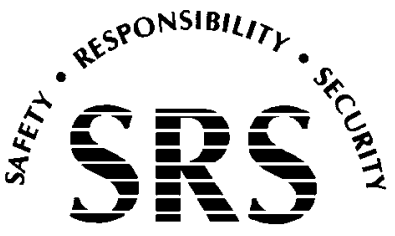

SAVANNAH RIVER SITE

Prepared for the U.S. Department of Energy Under

Contract Number DE-AC09-96SR18500 
This document was prepared in conjunction with work accomplished under Contract No. DE-AC09-96SR18500 with the U. S. Department of Energy.

\section{DISCLAIMER}

This report was prepared as an account of work sponsored by an agency of the United States Government. Neither the United States Government nor any agency thereof, nor any of their employees, makes any warranty, express or implied, or assumes any legal liability or responsibility for the accuracy, completeness, or usefulness of any information, apparatus, product or process disclosed, or represents that its use would not infringe privately owned rights. Reference herein to any specific commercial product, process or service by trade name, trademark, manufacturer, or otherwise does not necessarily constitute or imply its endorsement, recommendation, or favoring by the United States Government or any agency thereof. The views and opinions of authors expressed herein do not necessarily state or reflect those of the United States Government or any agency thereof.

This report has been reproduced directly from the best available copy.

Available for sale to the public, in paper, from: U.S. Department of Commerce, National Technical Information Service, 5285 Port Royal Road, Springfield, VA 22161, phone: (800) 553-6847, fax: (703) 605-6900

email: orders@ntis.fedworld.gov

online ordering: http://www.ntis.gov/help/index.asp

Available electronically at http://www.osti.gov/bridge

Available for a processing fee to U.S. Department of Energy and its contractors, in paper, from: U.S. Department of Energy, Office of Scientific and Technical Information, P.O. Box 62, Oak Ridge, TN 37831-0062,

phone: (865)576-8401,

fax: (865)576-5728

email: $\underline{\text { reports@ adonis.osti.gov }}$ 
Key Words:

XAFS

Zeolites

Sodalite

Clarkeite

Retention:

Permanent

\title{
Characterization of Uranium in Archived 2H Evaporator Scale
}

\author{
Martine C. Duff, Douglas B. Hunter, William R. Wilmarth \\ and Arthur Jurgensen
}

REPORT DATE: FEBRUARY 24, 2004

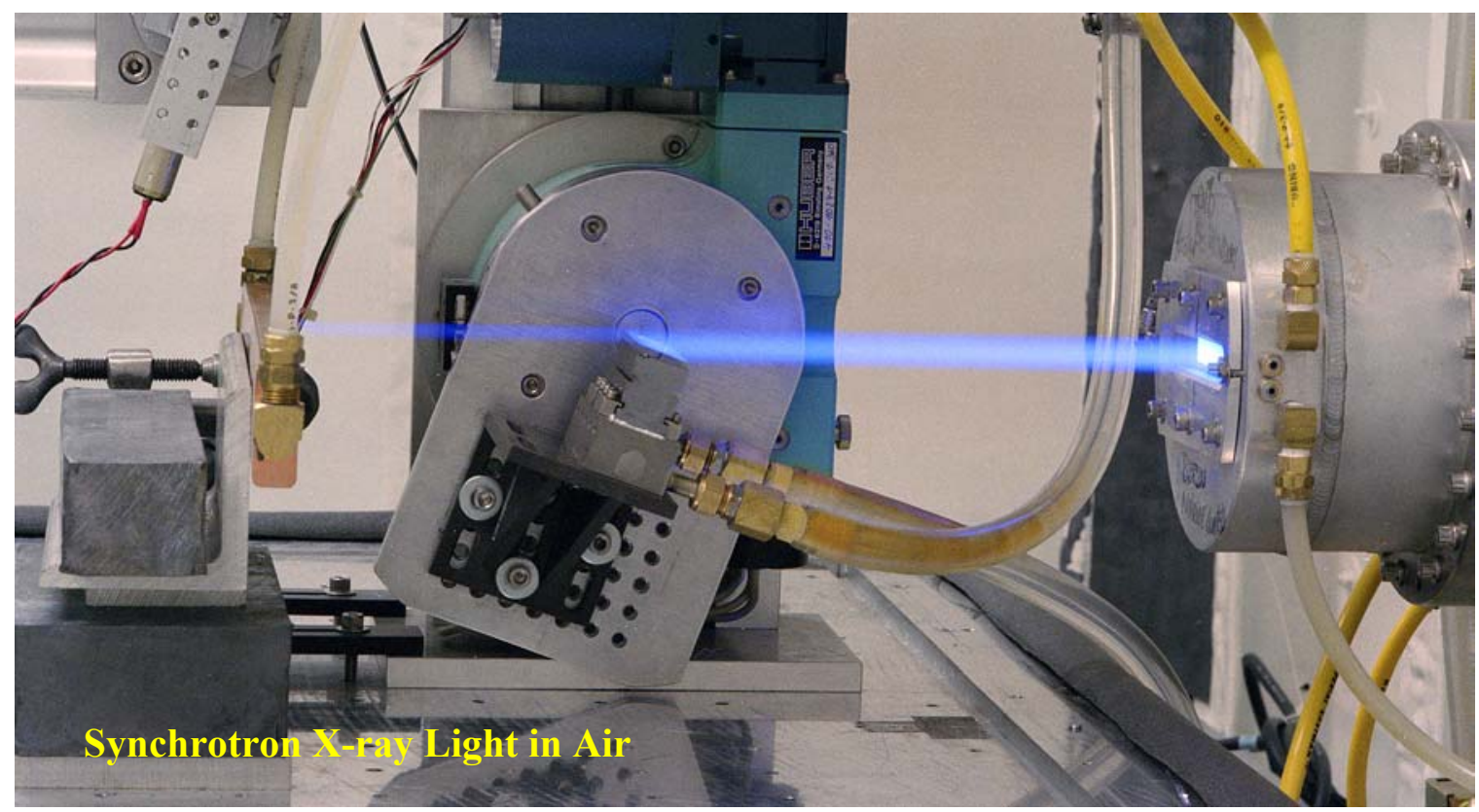

Westinghouse Savannah River Company

Savannah River Site

Aiken, SC 29808

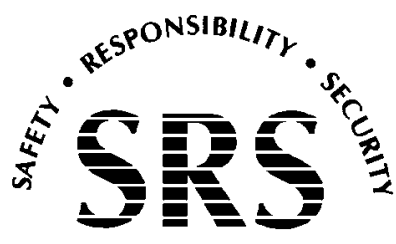

Prepared for the U.S. Department of Energy Under

Contract Number DE-AC09-96SR18500 
This page was intentionally left blank 


\section{TABLE OF CONTENTS}

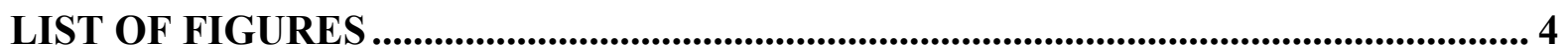

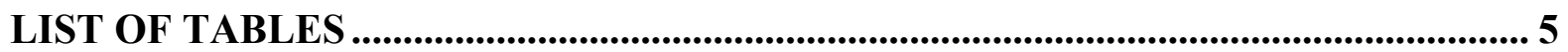

ACRONYMS and Abbreviations ............................................................................................ 6

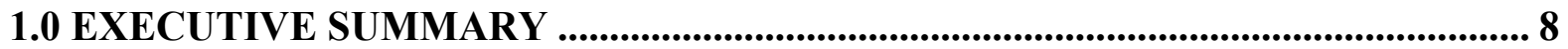

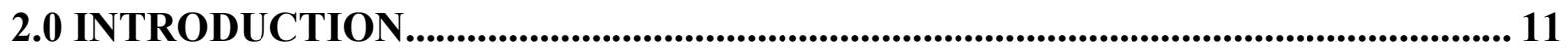

2.1 Potential Routes of U Accumulation with NAS ................................................................... 11

2.2 Review of Uranium(VI) Chemistry.................................................................................... 14

2.3 Speciation of Sorbed Uranium on Oxides and Zeolites ....................................................... 16

2.4 Use of XAFS Techniques to Characterize Metal Uptake by Surfaces............................ 16

2.5 Background on the Characterization of U Behavior with Solid Phase Surfaces using

XAFS and Related Techniques.............................................................................................. 16

2.5.1 Sorbed U(VI) Forms................................................................................................................. 17

2.5.2 U(VI) Co-precipitate Forms .............................................................................................. 17

2.5.3 U(VI) Precipitate Forms .......................................................................................................... 20

2.5.4 Uranium Speciation in HLW Systems............................................................................ 20

2.6 Experimental Objectives.............................................................................................................. 20

3.0 MATERIALS AND EXPERIMENTAL METHODS...................................................... 22

3.1 Elemental and Isotopic Characterization of Sample............................................................... 22

3.2 XRD Data Collection and SEM Imaging............................................................................... 22

3.3 Sample Preparation for XAFS ........................................................................................... 23

3.4 EXAFS Data Collection.......................................................................................................... 23

3.5 EXAFS Data Analyses............................................................................................... 26

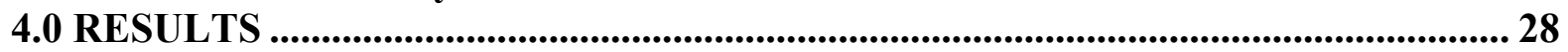

4.1 Elemental and Isotopic Characterization of 2H-Evaporator Scale after Sample

Digestion ............................................................................................................................................ 28

4.2 Characterization of 2H-Evaporator Scale using XRD and SEM Microscopy

Techniques.................................................................................................................................... 30

4.2.1 Uranium XANES Data for the 2H-Evaporator Scale .................................................... 34

4.2.2 Uranium Chi Data for the 2H-Evaporator Scale ......................................................... 34

4.2.3 Uranium Fourier-Transformed Data for the 2H-Evaporator Scale ........................ 37

4.2.4 Uranium FT and Model Fit Data for the 2H-Evaporator Scale ............................... 38

4.2.5 Discussion of the Influence of Silica on Total Solution $U$, $U$ Accumulation and

Solid Phase U Speciation........................................................................................................... 41

4.2.5.1 Interactions of Caustic Solution with Silica ...................................................... 42

4.2.5.2 Tank 43 Evaporator Feed Data ............................................................................ 42

4.2.5.3 Accumulation of Silica in the $2 \mathrm{H}$ Evaporator ......................................................... 43

4.2.5.4 Clarkeite Association with Uranyl Silicates in Natural Environments Rich in

$\mathrm{Na}, \mathrm{U}$ and $\mathrm{Si}$...................................................................................................................... 43

4.2.5.5 Summary of Interactions that Relate to the Deposition and Accumulation of $U$

and Silica in Scale ....................................................................................................................... 43

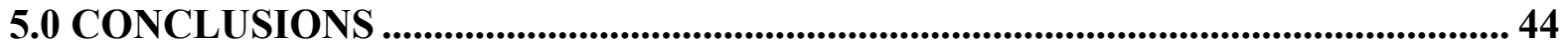

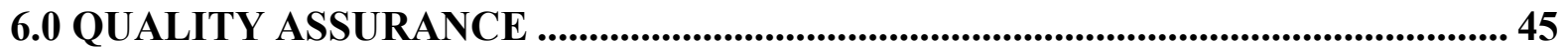

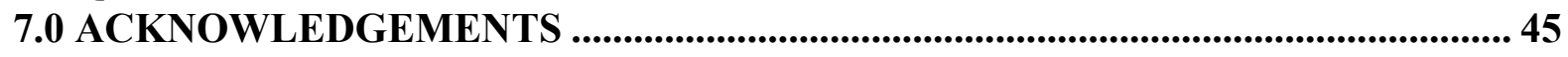

8.0 REFERENCES................................................................................................................. 46 


\section{LIST OF FIGURES}

Figure 2-1 Simplified diagram of the types of associations a metal could have with a surface: A)

Structural incorporation/co-precipitation, B) Outer-sphere (electrostatic) sorption, C)

Specific or inner-sphere sorption and D) Surface precipitation. Blue rings denote first, second and third shell environments that can be probed with XAFS spectroscopic

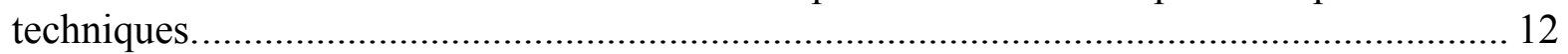

Figure 2-2 Pictorial representation of possible U interactions with NAS and related solids. ...... 14

Figure 2-3 The two types of first shell bonding environments for U(VI). Some U(VI) solids with "uranate" in their names such as sodium diuranate consist of uranyl-type bonding. Hence, the name of the solid does not always describe the nature of the bonding. Clarkeite, which is referred to as a partially hydrated form of sodium diuranate has a split first coordination shell with two $1.89 \AA$ " "axial” type O's and six $2.30 \AA$ “"equatorial” type O's. ............................. 15

Figure 2-4 Pictorial representation of U(VI) edge and corner sharing with silica tetrahedra....... 19 Figure 2-5 Examples of uranyl silicate structures. Red arrows denote radial U-U distances that can be obtained using crystallographic and XAFS analyses.......................................... 21

Figure 3-1 Pictures of the archived 2H scale material used in this study................................. 22

Figure 3-2 Image of the components used in the primary sample holders. Once assembled with eight metal screws, these primary holders are placed on a motorized stage, which is then placed in a sealed metal box. The sealed metal box also serves as additional containment for the samples during handling and analyses. ........................................................... 24

Figure 3-3 Image of two of the intact primary sample holders that were used to contain the $2 \mathrm{H}-$ Evaporator scale.

Figure 3-4 Picture of the sample stage that is placed inside a large aluminum box. The stage is motor controlled. It permits the controlled raising or lowering of the stage to allow one to move from sample to sample without having to breach the containment.......................... 25

Figure 3-5 Picture of the aluminum metal box that was used to contain the 2H-Evaporator scale samples in their primary containment and to hold the motor-controlled sample stage......... 25

Figure 3-6 The beam line endstation setup at Bending Magnet 12 at the Advanced Photon

Source. The multielement detector that was used is not shown in this picture. The aluminum metal sample box that contained the radioactive samples is shown and positioned between two ion chambers ( $I o$ and $I t$ ). 26

Figure 3-7 Diagram of BM-12 at the Advanced Photon Source (not drawn to scale). Bending magnet and other upstream portions of the X-ray ring not shown.

Figure 4-1 XRD characterization data for the two replicate samples [A) and B)] of the archived $2 \mathrm{H}$-evaporator scale.

Figure 4-2 XRD characterization data for the 2H-Evaporator scale from Wilmarth et al. 2000. These spectra show the improved fit that is obtained using A) clarkeite instead of B) sodium diuranate.

Figure 4-3 SEM photomicrograph of 2H-Evaporator scale. Red arrows denote U-rich areas with minor $\mathrm{Na}, \mathrm{Al}$ and $\mathrm{Si}$. The blue arrow denotes what appears to be a cancrinite needle. This region has minor $\mathrm{U}$ and high levels of $\mathrm{Na}, \mathrm{Al}$ and $\mathrm{Si}$.

Figure 4-4 SEM photomicrograph of 2H-Evaporator scale. Red arrows denote U-rich areas with minor $\mathrm{Na}, \mathrm{Al}$ and $\mathrm{Si}$. Blue arrows denote regions with minor $\mathrm{U}$ and high levels of $\mathrm{Na}, \mathrm{Al}$ and $\mathrm{Si}$. The green arrow shows a region that is rich in $\mathrm{Fe}$ and $\mathrm{Cu}$. 
Figure 4-5 Normalized XANES spectra for $U$ in the two scale samples. 34

Figure 4-6 The $k^{2}$-weighted chi data (the plot of the wavevector in reciprocal space) for the $2 \mathrm{H}$ evaporator scale sample. 35

Figure 4-7 The $k^{2}$-weighted chi data (the plot of the wavevector in reciprocal space) for the $2 \mathrm{H}$ evaporator scale and the U-NAS co-precipitate samples from Duff, Hunter and Oji (2002). 35

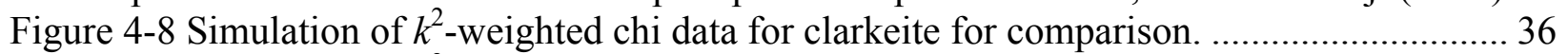

Figure 4-9 Simulation of $k^{2}$-weighted chi data for boltwoodite for comparison............................ 36

Figure 4-10 FT data for the archived 2H-Evaporator scale series samples - uncorrected for phase shift

Figure 4-11 FT and first coordination shell fit data for the 2H-Evaporator scale sample \#4uncorrected for phase shift.

Figure 4-12 FT and higher coordination shell fit data for the 2H-Evaporator scale Sample \#4uncorrected for phase shift. The red asterisk denotes outer shell peak that is consistent with interactions beyond the second and third shells. Fits of this peak in the FT data were not performed.

Figure 4-13. Atomistic views of the crystal structure of a synthetic uranyl silicate that was made hydrothermally in caustic solution. The $U$ in this solid has a similar first shell environment to that of the $\mathrm{U}$ in the $2 \mathrm{H}$ Evaporator scale.

\section{LIST OF TABLES}

Table 2-1 Literature XAFS fit data for sorbed U(VI) on characterized Al and Si minerals. The magnitude of the Debye-Waller (DW) Factor $\left[\sigma^{2}[\AA]^{2}\right]$ indicates the variation in the bond length determination.

Table 4-1 Average characterization data for ICP-AES analyses of the digested 2H Evaporator scale (based on single analyses of duplicate sample digestions). Values are $\pm 10 \%$ for all elements, with the exception of $\pm 12 \%$ for Si. Sodium was not analyzed for.. 28

Table 4-2 Average radiochemical data for analyses of the digested 2H-Evaporator scale (based on single analyses of duplicate sample digestions). The Pu analyses were performed using the $\mathrm{Pu}$-TTA extraction method with alpha radiometric counting. Strontium-90 was analyzed using scintillation analyses and the remaining isotopes were analyzed using gamma spectroscopy.

Table 4-3 Average characterization data for ICP-MS analyses of the digested 2H-Evaporator scale (based on single analyses of duplicate sample digestions). The calculated isotopic abundance for the ${ }^{235} \mathrm{U} /{ }^{(235+238)} \mathrm{U}$ was $2.22 \%$. The large error in the ${ }^{238} \mathrm{U}$ is due to error from the sample and not the instrument. 


\section{ACRONYMS AND ABBREVIATIONS}

Al

Am

APS

$\mathrm{Ca}$

$\mathrm{CO}_{3}{ }^{2-}$

$\mathrm{CN}$

$\mathrm{Cu}$

$\delta(\mathrm{K})$

DDL

DI

DW

DWPF

EXAFS

E

$\mathrm{E}_{0}$

$\mathrm{E}_{0}$ Shift

$\mathrm{F}$

$\mathrm{Fe}$

FEFF

FFIT

FT

$\hbar$

$\mathrm{Hg}$

HLW

IIT

$k$

$\mathrm{m}$

MST

$\mathrm{Na}$

NAS

$\mathrm{Na}_{4}\left(\mathrm{UO}_{2}\right)\left(\mathrm{O}, \mathrm{OH}_{2}\right)_{2(\mathrm{~s})}$

$\mathrm{Na}_{2} \mathrm{U}_{2} \mathrm{O}_{7(\mathrm{~s})}$

$\mathrm{Na}_{2}\left(\mathrm{UO}_{2}\right)_{2}\left(\mathrm{SiO}_{3} \mathrm{OH}\right)_{2} \cdot 1.5 \mathrm{H}_{2} \mathrm{O}$

$\mathrm{Na}_{2}\left(\mathrm{UO}_{2}\right)_{2}\left(\mathrm{Si}_{5} \mathrm{O}_{13}\right)_{6} \cdot 3 \mathrm{H}_{2} \mathrm{O}$

$\mathrm{Ni}$

$\mathrm{Np}$

$\mathrm{O}$

$\mathrm{Pu}$

R-space
Aluminum

Americium

Advanced Photon Source

Calcium

Carbonate ion

Coordination number

Copper

Electronic phase shifts due to atomic potentials

Diffuse Double Layer

De-ionized water

Debye-Waller Factor

Defense Waste Processing Facility

Extended X-ray Absorption Fine-Structure

$E$ is the kinetic energy of the photoelectron

EXAFS defined edge energy in electron volts or eV (not equal to edge energy as defined by XANES but is equal to the energy of the photoelectron at $k=0$.

A relative value of $E_{0}$ (a variable in the EXAFS Equation)

Backscattering amplitude of the atom

Iron

An automated computer program for making ab initio multiple scattering calculations of XAFS and XANES spectra for atoms.

A Levenberg-Marquardt fitting program created by researchers at the University of Washington

Fourier-transform

Plank's constant

Mercury

High Level Waste

Illinois Institute of Technology

Chi where $k$ is the square root of $\left[\left(2 \mathrm{~m} / \hbar^{2}\right) *\left(\mathrm{E}-\mathrm{E}_{0}\right)\right]$

Mass of the photoelectron

Monosodium titanate

Sodium

Sodium aluminosilicates

Clarkeite

Sodium diuranate

Na-boltwoodite

Na-weeksite

Nickel

Neptunium

Oxygen

Plutonium

$\mathrm{R}$-space pertains to mean atom position or bond distance (radial distance in $\AA$ ) 


$\mathrm{RDF}$
$\mathrm{S}$
$\mathrm{Sb}$
$\mathrm{S} 0^{\wedge} 2$ or $\mathrm{S}_{0}{ }^{2}$
$\sigma^{2}$ or $\mathrm{SIGMA}^{2}$
$\mathrm{Si}$
$\mathrm{S} / \mathrm{N}$
$\mathrm{SME}$
$\mathrm{Sn}$
$\mathrm{Sr}$
$\mathrm{SRTC}$
$\mathrm{Th}$
$\mathrm{U}$
$(\mathrm{UO})_{2} \mathrm{SiO}_{4} \cdot 2 \mathrm{H}_{2} \mathrm{O}_{(\mathrm{s})}$
$\mathrm{U}(\mathrm{VI})$
$\mathrm{U}(\mathrm{VI}) \mathrm{O}_{3} \cdot 2 \mathrm{H}_{2} \mathrm{O}_{(\mathrm{s})}$
$\mathrm{WSRC}$
$\mathrm{XAFS}$
XANES
$\mathrm{XRD}$
$\mathrm{Y}$
$\mathrm{ZOT}$
$\mathrm{Zr}$

Radial Distribution Function

Sulfur

Antimony

Amplitude reduction factor (EXAFS Equation variable associated with central atom shake-up and shake-off effects)

Debye-Waller Factor or Relative Mean Square Disorder in bond length (a variable in the EXAFS Equation)

Silica (or silicon)

Signal-to-noise

Slurry Mix Evaporator (part of the DWPF)

Tin

Strontium

Savannah River Technology Center

Thorium

Uranium

Soddyite

Hexavalent uranium

Schoepite, a uranyl oxyhydroxide mineral

Westinghouse Savannah River Company

X-ray Absorption Fine-Structure (XANES plus EXAFS)

X-ray Absorption Near-Edge Structure

X-ray Diffraction

Yttrium

Zone of Turbidity

Zirconium 


\subsection{EXECUTIVE SUMMARY}

At the Savannah River Site (SRS), the High-Level Waste (HLW) Tank Farms store and process high-level liquid radioactive wastes from the Canyons and recycle water from the Defense Waste Processing Facility (DWPF). The waste is concentrated using evaporators to minimize the volume of space required for HLW storage. After evaporation, the waste concentrate is transferred to one or more receipt storage tanks. Recently, the $2 \mathrm{H}$ Evaporator was shutdown due to crystallization of sodium aluminosilicates (NAS) (such as cancrinite, sodalite, zeolite A and various zeolite precursor materials) that contained enriched uranium (U) solids. Prior to shutdown, the $2 \mathrm{H}$ Evaporator received high amounts of silica (originating from the DWPF recycle) from Tank 43 (from 1996 to 2001), which was the feed tank for the 2 H Evaporator. The evaporator deposits resided on the evaporator walls and other exposed internal surfaces within the evaporator pot. The $2 \mathrm{H}$-Evaporator scale deposits were later removed by leaching with nitric acid. $^{1}$

This research was conducted to improve our fundamental understanding of the mechanisms of $U$ accumulation with NAS in the evaporators and in other process areas at the SRS that may concentrate $U$ in the presence of silicates, aluminum and NAS. Our study uses information gained from the characterization of solids formed in laboratory tests under similar HLW evaporator conditions to aid our interpretation of characterization data of an actual archived $2 \mathrm{H}$ Evaporator scale sample. These basic scientific studies will help support the basis for the continued safe operation of SRS evaporators and this fundamental information will be used to help mitigate $\mathrm{U}$ accumulation during evaporator operation.

To characterize the U associated with the NAS solids in scale, Savannah River Technology Center (SRTC) conducted tests to examine the local structural speciation of $U$ in a wellcharacterized archived evaporator scale sample from the sidewall of the $2 \mathrm{H}$ Evaporator. The solids were analyzed using analytical techniques such as radiometric, elemental (mass spectrometric), X-ray diffraction (XRD), scanning electron microscopy (SEM) analyses and Xray absorption fine-structure (XAFS) spectroscopic techniques. The XAFS techniques include X-ray absorption near-edge structure (XANES) and extended X-ray absorption fine structure (EXAFS) studies. The studies yielded the following information about the characterization of the evaporator scale sample:

- Inductively-coupled plasma mass spectrometry (ICP-MS) measurements indicate that the U concentration is about $5.6 \mathrm{wt} \%$ with a $2.22 \%$ isotopic enrichment $\left({ }^{235} \mathrm{U} /{ }^{(235+238)} \mathrm{U}\right)$ based on duplicate analyses. ICP-MS measurements of the Tc levels in the solutions were below detection (less than $1 \mathrm{mg}^{99} \mathrm{Tc} \mathrm{kg}^{-1}$ ).

- Radiochemical analyses indicate the dominant alpha particle emitter in the scale is ${ }^{238} \mathrm{Pu}$ relative to ${ }^{239 / 240} \mathrm{Pu}$. However, the total $\mathrm{Pu}$ levels in the scale are roughly $400 \mathrm{mg} \mathrm{Pu} \mathrm{kg}{ }^{-1}$ scale. As is typical for most high-level waste forms, the dominant beta emitters in the scale are ${ }^{90} \mathrm{Sr},{ }^{90} \mathrm{Y}$, and ${ }^{137} \mathrm{Cs}$; and the dominant photon emitter is ${ }^{137 \mathrm{~m}} \mathrm{Ba}$, the short-lived decay product of ${ }^{137} \mathrm{Cs}$. 
- The XRD analyses of the archived sample from the evaporator wall identified clarkeite as a crystalline phase and the presence of unidentified amorphous material, which is probably amorphous silica in the archived scale samples. XRD analyses also identified the crystalline zeolite solids: sodalite and cancrinite. Comparison of our XRD data with that of previous $\mathrm{XRD}$ data for $2 \mathrm{H}$ Evaporator scale indicate that clarkeite is the dominant crystalline $\mathrm{U}$ phase and that NAS solids comprise the remainder of the crystalline phases in the scale. However, the older XRD characterization data for a sample from the evaporator pot do not exhibit a significantly broad baseline, which we would attribute to being from amorphous material such as silica. The XRD data from these two samples suggest that the scale samples are different and that the $2 \mathrm{H}$ Evaporator scale contains heterogeneous distribution of solid phase U species. Some explanation for the heterogeneity could be due to differences in temperature and the amount of exposure to washes with inhibited water (to remove scale deposition).

- $\quad$ SEM studies indicate that the $U$ in the archived scale is typically found in two particle micro morphologies: as U-rich solids with minor sodium/silicon/aluminum $(\mathrm{Na} / \mathrm{Si} / \mathrm{Al})$ and $\mathrm{Na} / \mathrm{Si} / \mathrm{Al}$-rich solids with minor U. Other types of solids that are rich in one or more of the following elements: iron $(\mathrm{Fe})$, copper $(\mathrm{Cu})$, nickel $(\mathrm{Ni})$ and mercury $(\mathrm{Hg})$ are observed but these solids do not contain as much $\mathrm{U}$ as the other solids.

- Uranium X-ray absorption near-edge structure or XANES spectroscopic studies indicate that $\mathrm{U}$ is present as the $\mathrm{U}(\mathrm{VI})$ or hexavalent species in the archived scale. This $\mathrm{U}$ species is common in oxidized systems.

- In contrast to the XRD analyses, our U-XAFS analyses, which characterize both amorphous (including sorbed) and crystalline phases did not identify clarkeite to be a dominant uranyl phase of $U$ in the scale. Uranium-XAFS analyses identified the existence of a phase that has uranyl-type first shell environment, with two axial oxygen $(\mathrm{O})$ atoms at a distance at $1.85 \AA$ and four equatorial $\mathrm{O}$ atoms at a distance of $2.19 \AA$. [In contrast, clarkeite has six equatorial $\mathrm{O}$ atoms.] The outer shell environment contains two Si atoms at $3.85 \AA$ and three U atoms at $4.13 \AA$. If clarkeite were a dominant solid phase in the sample, $\mathrm{Na}$ should be readily visible in the local coordination shell (i.e., the XAFS spectra). However, it was not detectable. The absence of $\mathrm{Na}$ in the XAFS supports the assignment of one or more dominant $U$ phases other than clarkeite.

- The long U-Si radial distances observed are indicative of structural (i.e., corner-sharing linkages between U and Si tetrahedra) and are not representative of sorbed U(VI) on NAS, which has edge-sharing linkages between $U$ and Si tetrahedra. Hence, these data indicate that the $U$ in the scale is not sorbed $U$ as mono or dimeric species - as is consistent for most sorbed uranyl species on aluminosilicates. The observed corner-sharing by $\mathrm{U}$ with $\mathrm{Si}$ tetrahedra is indicative of a precipitated or polymeric form of $U$. Additionally, the large amount of $U$ that is found in the outer coordination shell of $U$ at $4.13 \AA$ indicates that a precipitated form of $U$ dominates the spectra rather than a sorbed polymeric $U$ species, as observed in the literature. 
- According to the XRD and XAFS data analyses, the $\mathrm{U}$ in the 2H-Evaporator scale exists in at least two solid phase forms: a partially-hydrated crystalline (VI) species called clarkeite $\mathrm{Na}_{4}\left(\mathrm{UO}_{2}\right)\left(\mathrm{O}, \mathrm{OH}_{2}\right)_{2(\mathrm{~s})}$ and an amorphous $\mathrm{U}(\mathrm{VI})$-silica phase.

- The dominance of an amorphous U-silica form of $U$ in recently deposited NAS (evaporator wall) material and the absence of this form of $U$ in older (more cycled) NAS (evaporator pot) scale deposits provide information that supports the following proposed mechanism: the amorphous U-silica material has a high propensity to physically adhere or "stick" to NAS and with ageing and evaporator recycling, much of this U-silica material in the scale eventually converts to clarkeite.

- Evaporator feed wastes that are rich in colloidal (i.e., saturated) silica or contain undissolved frit are likely to support U-silica formation over clarkeite formation in the feed prior to entrance into the evaporator. More specifically, evaporator feed wastes taken from slightly above the sludge layer such as in the "zone of turbidity" or ZOT of Tank 43, which was the feed tank prior to $2 \mathrm{H}$ Evaporator shut-down due to scale formation in $1999^{2}$ are likely to support $U$ and silica interactions. The high levels of $U$ in the near ZOT material may also be due to entrained sludge, which associates with the silica-rich material. However, our present study, which focused on the characterization of the $2 \mathrm{H}$ scale, did not characterize the Tank 43 feed material and without characterization data on that material (i.e., U XAFS data) we cannot be certain about the behavior of the $U$ in the feed material during prior to shut-down in 1999.

- The presence of highly saturated silica in caustic solutions that are not in thermodynamic equilibrium, such as poorly mixed solutions or wastes containing undissolved frit, are likely to have much higher dissolved or total U concentrations due to U-silica colloid formation. The presence of high silica in these systems may convert solid phase $U$ (in the form of a sodium diuranate (clarkeite) saturated solution) into a more saturated U-silica solution, which is highly colloidal in nature. Due to its colloidal nature, this material may readily pass through a filter and produce higher than expected "dissolved" U concentrations. ${ }^{3}$ It would also contribute to higher than expected $U$ concentrations in unfiltered feed solution samples. Again, it is also possible that the high levels of $U$ in the near ZOT material may also be due to entrained sludge, which is suspended within the silica-rich gel material in Tank 43. 
WSRC-TR-2004-00016, REVISION 0

\subsection{INTRODUCTION}

\subsection{Potential Routes of U Accumulation with NAS}

Uranium accumulation during the evaporation of HLW is a potential criticality risk if the incoming waste is enriched in ${ }^{235} \mathrm{U}$. During evaporation, several processes may contribute to the accumulation of U-containing solids as shown pictorially in Fig. 2.1 and 2.2. [Note: Fig. 2.1 demonstrates potential U interactions with NAS on the molecular scale whereas Fig. 2.2 shows more of a conceptual or cartoon-like diagram of potential U interactions with NAS solids.] This report will operationally define the various uptake mechanisms according to the following text descriptions.

During the evaporation of caustic $\mathrm{Na}^{+}$-rich solutions, several processes could potentially contribute to the accumulation of U-containing solids. Uptake processes by solids can occur by several mechanisms: structural incorporation, ion exchange (electrostatic or outer-sphere) sorption, specific adsorption and surface precipitation/polymerization. Figure 2.1A-D demonstrates potential U interactions with NAS on the molecular scale. The blue rings denote the local coordination shell environments that can be detected and characterized using XAFS spectroscopic techniques. Typically, the expression of these uptake processes depends upon the amount of metal added, solution and solid phase characteristics. ${ }^{4,5}$

"Ion exchange" can have different meanings, which results in some confusion in the literature. One very general way to express ion exchange is Structural Incorporation, which is the substitution of a solution species for a structural atom as shown in the example below for strontium $(\mathrm{Sr})$ ion substitution for calcium $(\mathrm{Ca})$ ion in calcite [calcium carbonate, $\mathrm{CaCO}_{3(\mathrm{~s})}$ ].

$$
\mathrm{CaCO}_{3(\mathrm{~s})}+\mathrm{Sr}^{2+} \longleftrightarrow \mathrm{SrCO}_{3(\mathrm{~s})}+\mathrm{Ca}^{2+}
$$

This type of metal uptake typically requires ready access to structural atoms. An example of this process would be the exchange of $\mathrm{Na}^{+}$for $\mathrm{Ca}^{2+}$ within the interlayer region of a layered metal oxide material. Structural incorporation includes co-precipitation, where a new atom substitutes for host structural atoms during the formation of the host solid. Ideally, structural incorporation of anions could also occur. Therefore, the local environment of the exchanged atom(s) would resemble the environment that of the newly exchanged atom prior to its release into solution (Fig. 2.1A). Two exceptions to this would be when the host structure is a nanoparticle (i.e., of vary small dimension) and when the structure is amorphous or structure-less. In these cases, exact determinations of whether the participating metal species resides in a structural vacancy or within an interlayer site are not straightforward. ${ }^{6}$

Ion Exchange in a more restrictive sense as used in this study is an electrostatic process involving the replacement of one readily exchangeable hydrated ion by another similarly exchangeable ion (Fig. 2.1B). This type of sorption is also referred to in the literature as Outer Sphere sorption. It does not involve the formation of bonds with the participating surface because the sorbed ion is only present in the diffuse double layer (DDL). This type of outer 


\section{Molecular/Atom Scale Metal Interactions with Surfaces}

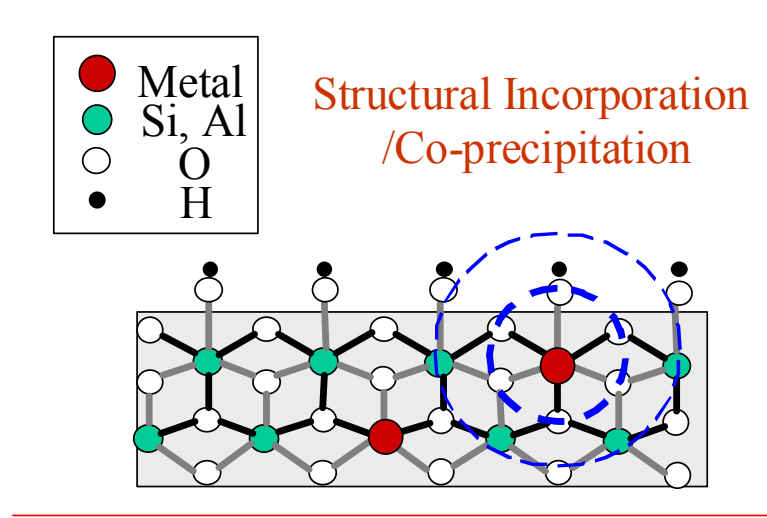

Specific Adsorption/ Chemisorption / Inner Sphere Sorption

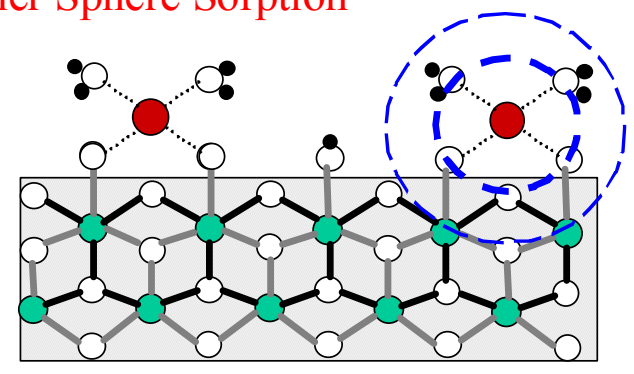

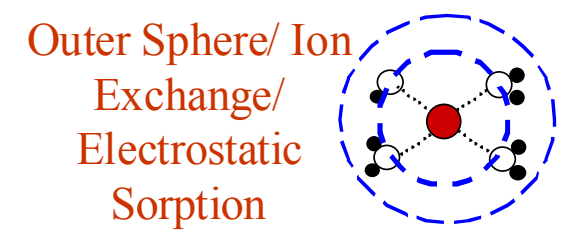

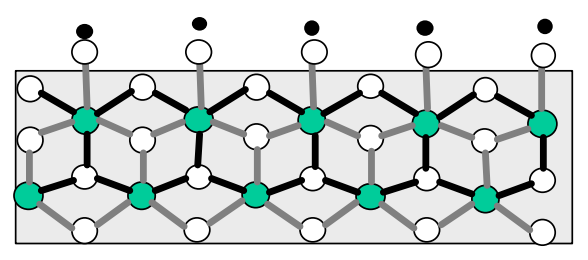

Surface Precipitation/Polymerization

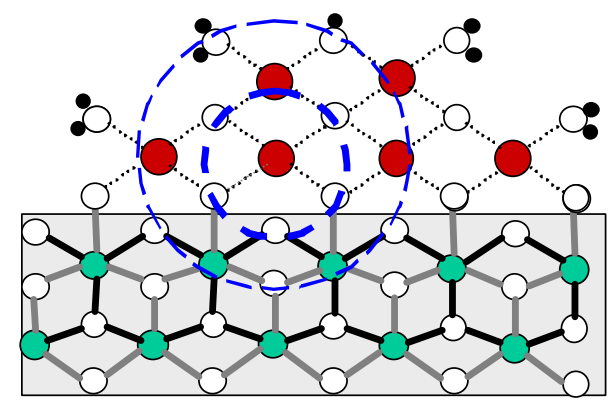

Blue circles denote coordination shells.

Figure 2-1 Simplified diagram of the types of associations a metal could have with a surface: A) Structural incorporation/co-precipitation, B) Outer-sphere (electrostatic) sorption, C) Specific or inner-sphere sorption and D) Surface precipitation. Blue rings denote first, second and third shell environments that can be probed with XAFS spectroscopic techniques.

sphere sorption is normally reversible ${ }^{7}$ and is a function of ionic strength (i.e., such as $\mathrm{Na}^{+}$ion concentration). Ion exchange sorption is often associated with materials that have constant surface charge and exhibit no change in overall surface charge upon ion exchange. An example of this process is the exchange of two hydrated $\mathrm{Na}^{+}$ions for one hydrated $\mathrm{UO}_{2}{ }^{2+}$ ion (also called the uranyl ion) in the DDL.

Specific Adsorption (often referred to as Chemisorption or Inner Sphere sorption) involves the formation of predominantly covalent bonds with the surface, but the bonds can have some ionic behavior. These adsorbed metals typically have one or more atoms from the participating surface in the second coordination shell (Fig. 2.1C). This type of sorption involves the release of $\mathrm{H}^{+}$or structural surface ions such as $\mathrm{Na}^{+}$upon sorption. For example, specific sorption of $\mathrm{UO}_{2}{ }^{2+}$ to NAS could result in the presence of $\mathrm{Si}$ and $\mathrm{Al}$ atoms in the second coordination shell of the 
$\mathrm{UO}_{2}{ }^{2+}$. Specific adsorption is usually irreversible. ${ }^{8}$ However, in the literature, specific adsorption is not always differentiated from structural incorporation or surface precipitation. Specific adsorption may involve mononuclear complexes or polymeric species. It may occur with metals and their associated ligands [such as a U(VI)-carbonate ion] and it is influenced by other solution- and surface-related variables.

Surface Precipitation occurs by nucleation of new solid phase on a host surface (Fig. 2.1D). For example, when the concentration of a dissolved metal such as $\mathrm{UO}_{2}{ }^{2+}$ is high enough to result in the super-saturation of one or more $\mathrm{UO}_{2}{ }^{2+}$-containing phases [such as schoepite, which has a formula of $\mathrm{U}(\mathrm{VI}) \mathrm{O}_{3} \cdot 2 \mathrm{H}_{2} \mathrm{O}_{(\mathrm{s})}$ ] in the presence of another solid, the other solid may facilitate the nucleation of a new solid $\mathrm{UO}_{2}{ }^{2+}$-rich phase. This U-rich material would have numerous $\mathrm{U}$ atoms in the second or third coordination shell of the $U$. The formation of colloidal (polymeric) $U$ species on surfaces could resemble the same local environment (on the atom scale) as observed for surface precipitation. When atoms from a potential host surface are absent and polymeric species are present, the mechanism of $U$ uptake from solution is likely to be direct homogeneous (solid phase) precipitation. A crystalline $U$ form not associated with another separate mineral surface would be identifiable based on its crystal structure and the positions and identities of the atoms in that structure. This information is obtained from structural refinements of X-ray diffraction (XRD) data and from XAFS data.

Uranium may be concentrated by sorption to the surfaces of the NAS, precipitation within NAS structures and precipitation as $U$ phases. These processes are illustrated in a more simplistic manner in Fig. 2.2A-E, which emphasizes the potential interactions U can have with NAS. Sorption, as previously discussed can be divided into two types of molecular scale processes that involve the uptake of atoms near or at a participating sorptive surface (Fig. 2.2A). Uranium could co-precipitate with the NAS and related solids as shown pictorially in Fig. 2.2B. [For zeolites, the term co-precipitation could be sub-divided to include uptake into zeolite channels and any isomorphic substitution (i.e., of $\mathrm{U}$ for $\mathrm{Si}$ or $\mathrm{Al}$ ) in the zeolite structure. ${ }^{9}$ ] Uranium could also deposit by precipitation via surface nucleation (often referred to as chemical seeding) on NAS minerals (Fig. 2.2C). It is also possible that U solids could seed the growth of NAS solids (Fig. 2.2C). Uranium could potentially precipitate as an oxide [such as $\mathrm{UO}_{3(\mathrm{~s})}$ or $\mathrm{Na}_{2} \mathrm{U}_{2} \mathrm{O}_{7(\mathrm{~s})}$ ], a hydrous oxide [such as $\mathrm{Na}_{2}\left(\mathrm{UO}_{2}\right)_{3} \mathrm{O}_{3} \cdot(\mathrm{OH})_{2(\mathrm{~s})}$ ], and a silicate [e.g., $\left(\mathrm{UO}_{2}\right)_{2} \mathrm{SiO}_{4} \cdot 2 \mathrm{H}_{2} \mathrm{O}_{(\mathrm{s})}$ and $\mathrm{Na}_{4}\left(\mathrm{UO}_{2}\right)_{2} \mathrm{Si}_{4} \mathrm{O}_{10} \cdot 4 \mathrm{H}_{2} \mathrm{O}_{(\mathrm{s})}$ ] (Fig. 2.2D). ${ }^{10,}{ }^{11}$ Precipitation of $\mathrm{U}$ could occur simultaneously with the precipitation of NAS solids. This process is referred to as solid phase nucleation. ${ }^{4}$ Uranium precipitation could be independent of NAS formation. A molecular scale view of an example of a $\mathrm{U}$ precipitate is not presented in Fig. 2.2.

Uranium may also interact with silica sols, which have no defined crystal structure because of their amorphous nature (Fig. 2.2E). This interaction could possibly enhance U solubility by forming U-silica colloids, which appear (by analysis) to be dissolved because they are too small to be isolated by solution filtration. Alternatively, these sols may not pass a filter and therefore, there may be vast differences between total and filtered solution values of $U$ (and $\mathrm{Si}$ ). At an atom or molecular scale basis, this type of interaction with $U$ is best be described by the description of structural incorporation in Fig. 2.1A, which shows $U$ in a crystalline structuraltype environment. However, for colloidal Si, which is often very amorphous, the local 
A) Sorption of U on NAS (may facilitate nucleation of U solid phases)

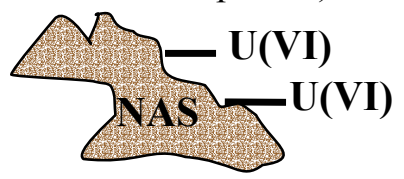

B) Co-precipitation of U within NAS structures

Aluminosilicate, $\mathrm{Na}+$

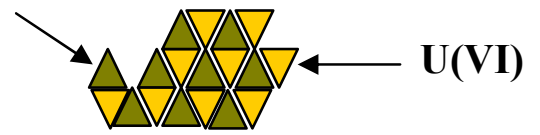

C) Growth of U solids on NAS solids and growth of

D) Precipitation of U as U(VI) oxide, oxide hydrate/uranate, silicate

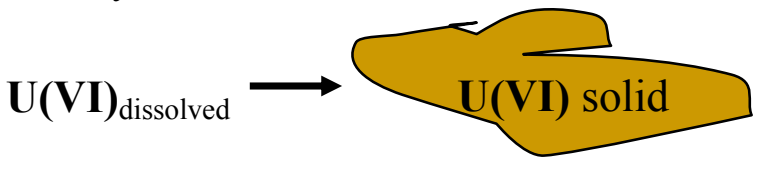

E) Silica sols may influence U solubility

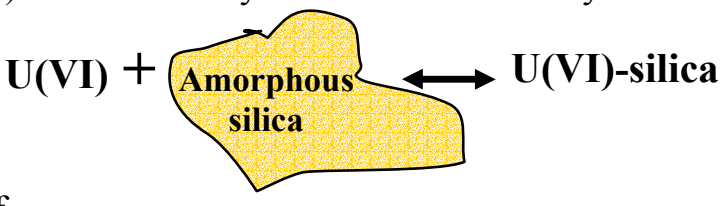
NAS solids on U solids (precipitation)
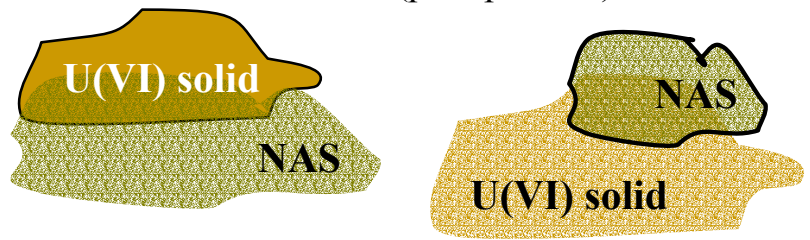

Figure 2-2 Pictorial representation of possible U interactions with NAS and related solids.

environment of the $U$ would not resemble an environment that has a crystalline uranium silicate structure.

\subsection{Review of Uranium(VI) Chemistry}

Dissolved U can exist in three forms: U(IV), U(V) and U(VI). In oxidized systems, dissolved U exists as the highly soluble uranyl $\left[\mathrm{U}(\mathrm{VI}) \mathrm{O}_{2}{ }^{2+}\right]$ species with two axial $\mathrm{U}=\mathrm{O}$ double bonds at lengths of $\sim 1.75$ to $1.80 \AA$ and four to six equatorial $\mathrm{U}-\mathrm{O}$ bonds at 2.25 to $2.48 \AA$. This uranyl form of U(VI) can exist in U solids or in solution. In aqueous solutions, the equatorial U-O atoms are typically bound to single atoms such as hydrogen (as hydroxo species). In the presence of dissolved ligands, the equatorial U(VI) atoms may form bridges with such atom groups as carbonate (as carbonato species) and nitrate (as nitrato species). [Depending on the solution $\mathrm{pH}$, ionic strength, ligand composition and availability, many combinations with U(VI) are possible.]

Solid phase U(VI) can also exist as the less common uranate-type form, which has at least three single U-O bonds. ${ }^{12,13,14}$ This form of U(VI) has not been documented to occur in the dissolved form. Uranate solids do not contain the short axial double U-O bonds (between $\sim 1.75$ to 1.85 $\AA$ ), that are characteristic of uranyl forms of U(VI). They contain at least three long U-O bonds in excess of about 2.1 to $2.3 \AA$. Additionally, uranate-type bonding is not common to all of the uranate solids. Some uranate solids possess uranyl behavior and some do not. ${ }^{15}$ A presentation of U(VI) bonding environments is shown in Figure 2-3. 


\section{Uranyl First Shell Structure}

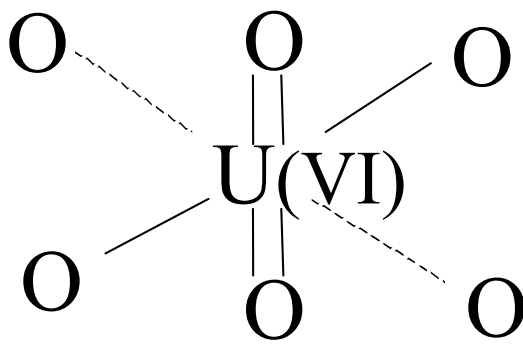

- 2 axial oxygen $(\mathrm{O})$ bonds at $\sim 1.75-1.80 \AA$.

- 4 (or more) equatorial $\mathrm{O}$ bonds at $\sim 2.25$ to $2.48 \AA$.

- Common form of U(VI).

- Example: $\mathrm{Na}_{4} \mathrm{UO}_{2}\left(\mathrm{CO}_{3}\right)_{3}$.
Uranate First Shell Structure

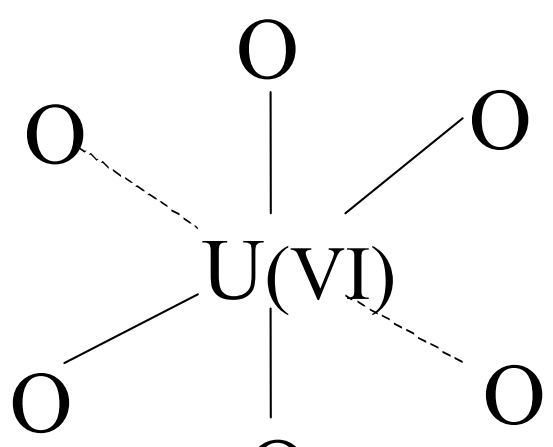

$\mathrm{O}$
- 3 or more O bonds usually at $\sim 2.1-2.3 \AA$. - Forms at temperature, structures poorly known.

- Aqueous solubility: < 100 ppm U but soluble in carbonate/acidic solutions. - U present as $\mathrm{U}^{6+}$ ion [0.52-0.86 $\AA$ ]. - Examples: $\mathrm{Ba}_{3} \mathrm{PuO}_{6}, \mathrm{CoUO}_{4}$ and glasses. Farges et al. 1992; Shannon 1976; Griffiths \& Volkovich, 1999.

Figure 2-3 The two types of first shell bonding environments for U(VI). Some U(VI) solids with "uranate" in their names such as sodium diuranate consist of uranyl-type bonding. Hence, the name of the solid does not always describe the nature of the bonding. Clarkeite, which is referred to as a partially hydrated form of sodium diuranate has a split first coordination shell with two $1.89 \AA$ “'axial” type O's and six $2.30 \AA$ “'equatorial” type O's. 


\subsection{Speciation of Sorbed Uranium on Oxides and Zeolites}

Several solid phases or sorbents such as the titanates (for example, monosodium titanate or MST) and metal oxides concentrate actinides and other radionuclides under conditions that are similar to alkaline HLW salt solutions. ${ }^{16,17,18,19}$ At high $\mathrm{pH}$, the surfaces of most solids are negatively charged and likely to sorb cationic species, such as $\mathrm{Sr}^{2+}$. Under these solution conditions most actinides such as U(VI) exist as negatively charged hydrolysis and carbonate $\left(\mathrm{CO}_{3}{ }^{2-}\right)$ species [such as $\left(\mathrm{UO}_{2}\right)_{2}(\mathrm{OH})_{5}{ }^{-}$and $\left.\mathrm{UO}_{2}\left(\mathrm{CO}_{3}\right)_{3}{ }^{4-}\right] .{ }^{20}$ When these U(VI) species dominate the solution speciation (at high $\mathrm{pH}$ or in high $\mathrm{CO}_{3}{ }^{2-}$ solutions), U(VI) typically has a low affinity for certain solids, such as the Fe oxides. ${ }^{21,22}$ Sorption of U(VI) species among other actinide species on sorbents such as the titanates occurs to a limited extent at high $\mathrm{pH}$. Sorption studies with U(VI) typically demonstrate that it has low affinity for zeolites at high $\mathrm{pH}(9-11)$ particularly in the presence of elevated inorganic carbon. ${ }^{23,24,25,26}$ This is because the higher levels of dissolved inorganic carbon favor the formation of negatively-charged, highly soluble U(VI)-carbonate complexes, which have low affinities for similarly-charged surfaces. Few sorption studies have been done with $\mathrm{U}$ and zeolites above $\mathrm{pH}$ 12. Spectroscopic studies with silicate gels indicate that $U$ sorbs via edge sharing with silica tetrahedra. ${ }^{27}$ This type of sorption to surface via edge linking (as opposed to corner linking) is typical for sorbed U(VI) species. ${ }^{28,} 29$

\subsection{Use of XAFS Techniques to Characterize Metal Uptake by Surfaces}

The local environment of metals associated with surfaces can be investigated with analytical techniques such as XAFS spectroscopy. It is an X-ray-based technique that is non-destructive and provides average information on bulk and surface behavior. The XAFS spectroscopic techniques are among the best for providing detailed chemical speciation information in environmental samples - particularly when information from multiple characterization techniques is available. The term XAFS is applicable to both X-ray absorption near-edge structure (XANES) and extended X-ray absorption fine-structure (EXAFS) spectroscopic techniques. XAFS spectra give robust local structural information on coordination number $(\mathrm{CN})$, bonding symmetry, neighbor and near-neighbor atomic distances and bond disorder (as the root mean square deviations of distances about the average values). Additionally, the information gained is atom specific - making it a versatile technique for structural determinations of atom clusters. $^{30,31}$ XAFS spectroscopy has been applied to the structural elucidation of metal clusters and sorbed metals on surfaces because the technique does not require long range order (i.e., periodicity) or crystalline samples. Hence, this technique can characterize colloidal forms of ions and species that would otherwise be undetected by XRD because of their poor crystalline behavior.

\subsection{Background on the Characterization of $U$ Behavior with Solid Phase Surfaces using XAFS and Related Techniques}

The information gained from XAFS studies that focus on the behavior of $U$ with surfaces can be used to determine the mechanism of $U$ accumulation. The XAFS techniques have been applied to the study of U(VI) on and within a variety of solids $13,29,32,33,34,35,36,37,38,39,40,41,42,43,44$ 
The findings of the sorption characterization studies vary greatly (based on surface, $\mathrm{pH}$, gas composition, temperature and U surface loading).

\subsubsection{Sorbed U(VI) Forms}

Sorbed $\mathrm{UO}_{2}{ }^{2+}$ species (in the absence of a redox-active mineral surface) typically form inner sphere bonds with the sorbent minerals over a solution $\mathrm{pH}$ range between 5 to 12 via primarily edge linking with octahedral or tetrahedral structural components. A list of the results for many of the XAFS studies on sorbed U species is shown in Table 2-1. The U(VI)-complexes that have been observed on surfaces using XAFS techniques are typically monomeric U(VI)-hydroxo and $\mathrm{U}(\mathrm{VI})$-carbonato species that form mono- and bidentate linkages with the participating surfaces (as noted in Fig. 2.4 and Table 2-1). Uranium(VI) species sorb mainly via an outer sphere mechanism on some silicates under acidic solutions. Layered smectitic (aluminosilicate) minerals typically sorb cations such as $\mathrm{Na}^{+}$and $\mathrm{Ca}^{2+}$, which form outer sphere (electrostatic) surface complexes on the fixed charge sites of basal planes of edge-sharing Al octahedra and edge-sharing Si tetrahedra as shown in Fig. 2-4. ${ }^{45}$ XAFS and wet chemical studies have elucidated that U(VI) sorbs on broken edge sites of layered aluminosilicate minerals, which possess $\mathrm{pH}$-dependent charge. ${ }^{46}$ Corner-linking in addition to edge-linking of sorbed $\mathrm{U}$ is observed at the muscovite (an aluminosilicate) surface. However, this aluminosilicate has a difference structure than that of zeolites. The surface sites on zeolites offer corner-linking sites through single terminal $\mathrm{O}$ atoms, as opposed to edge-linking sites, which occur through two $\mathrm{O}$ atoms. Hence, uranyl sorption to zeolites is limited to monomeric $U$ species due to steric limitations.

The local environment of sorbed U(VI) on muscovite was described using U-XAFS data and modeled by Moyes et al. (2000). ${ }^{32}$ They observed edge-sharing between the uranyl and a Si tetrahedron (i.e., the shortest U-Si radial distance). The longer U-Si distance was obtained by positioning a second neighboring corner-sharing Si tetrahedron next to the first edge-sharing $\mathrm{Si}$ tetrahedron. Hence, the bonding of uranyl was primarily through the edge-sharing Si tetrahedron that was also bonded to another Si tetrahedron. Other spectroscopic studies with silicate gels indicate that $U$ sorbs via edge-sharing with silica tetrahedral in acidic solutions. ${ }^{27}$

\subsubsection{U(VI) Co-precipitate Forms}

Some studies have examined the presence of $U$ in synthetic crystalline Fe oxide minerals and in zeolites that were synthesized at low $\mathrm{pH}^{28}$ These studies identified first shell $\mathrm{O}$ and outer shell Fe to exist at distances that are consistent with the $U$ existing within the structure of the $\mathrm{Fe}$ (III) oxide called hematite $\left(\mathrm{Fe}_{2} \mathrm{O}_{3}\right)$ - see Table 2-1. Outer shell U was not observed.

Studies that have synthesized zeolites in the presence of U(VI) under acid conditions show that uptake can occur and results in deformities within the zeolite structure. Under acidic conditions, these deformities permit $\mathrm{U}$ uptake at locations that would normally have $\mathrm{Na}^{+}$or $\mathrm{H}^{+}$ionsdepending on the form (i.e., $\mathrm{Na}^{+}$or $\mathrm{H}^{+}$) of the zeolite. ${ }^{9}$ Other studies that have examined the 
Table 2-1 Literature XAFS fit data for sorbed U(VI) on characterized Al and Si minerals. The magnitude of the Debye-Waller (DW) Factor $\left[\sigma^{2}[\AA]^{2}\right]$ indicates the variation in the bond length determination.

\begin{tabular}{|c|c|c|c|c|}
\hline Sample & Interaction & $\mathbf{C N}$ & $\begin{array}{c}\text { Distance } \\
\mathbf{R}[\AA]\end{array}$ & $\sigma^{2}[\AA]^{2}$ \\
\hline $\begin{array}{l}0.4 \mathrm{mM} \mathrm{U}(\mathrm{VI}) \text { sorbed to muscovite (an } \\
\text { layered aluminosilicate, } \mathrm{pH} 4.6)^{32, *} \\
\text { (Inner sphere) }\end{array}$ & $\begin{array}{c}\mathrm{U}-\mathrm{O}_{\mathrm{ax}} \\
\mathrm{U}-\mathrm{O}_{\mathrm{eq}} \\
\mathrm{U}_{-} i_{1} \\
\mathrm{U}-\mathrm{Si}_{2} \\
\mathrm{U}-\mathrm{U}\end{array}$ & $\begin{array}{l}2 \\
4 \\
1 \\
2 \\
1\end{array}$ & $\begin{array}{l}1.80 \\
2.35 \\
2.75 \\
3.66 \\
3.86 \\
\end{array}$ & $\begin{array}{l}0.003 \\
0.028 \\
0.011 \\
0.010 \\
0.010\end{array}$ \\
\hline $\begin{array}{l}\text { Natural U-rich Fe-Si oxide material }{ }^{42,} \\
\text { (Inner sphere) }\end{array}$ & $\begin{array}{c}\mathrm{U}-\mathrm{O}_{\mathrm{ax}} \\
\mathrm{U}-\mathrm{O}_{\mathrm{eq} 1} \\
\mathrm{U}_{\mathrm{eq} 2} \\
\mathrm{U}_{\mathrm{eq}} \mathrm{Si}_{1} \\
\mathrm{U}-\mathrm{Si}_{2} \\
\mathrm{U}-\mathrm{U}\end{array}$ & $\begin{array}{l}2.1 \\
1.8 \\
1.8 \\
0.1 \\
4.0 \\
1.6\end{array}$ & $\begin{array}{l}1.80 \\
2.32 \\
2.48 \\
3.29 \\
3.67 \\
3.81\end{array}$ & $\begin{array}{l}0.005 \\
0.005 \\
0.004 \\
0.001 \\
0.020 \\
0.009\end{array}$ \\
\hline $\begin{array}{l}\text { Amorphous silica gel, } 28 \mathrm{mg} \mathrm{U} \mathrm{kg}^{-1} \text { solid, } \\
\mathrm{pH} 4^{38} \\
\text { (Outer sphere) }\end{array}$ & $\begin{array}{l}\mathrm{U}-\mathrm{O}_{\mathrm{ax}} \\
\mathrm{U}-\mathrm{O}_{\mathrm{eq} 1} \\
\mathrm{U}-\mathrm{O}_{\mathrm{eq} 2}\end{array}$ & $\begin{array}{l}2.0 \\
2.2 \\
3.0\end{array}$ & $\begin{array}{l}1.80 \\
2.29 \\
2.51\end{array}$ & $\begin{array}{c}0.015 \\
0.0057 \\
0.0070\end{array}$ \\
\hline $\begin{array}{l}\text { Amorphous silica gel, } 59 \mathrm{mg} \text { U(VI) } \mathrm{kg}^{-1} \\
\text { solid, } \mathrm{pH} \sim 4{ }^{27} \text { (Outer sphere) }\end{array}$ & $\begin{array}{l}\mathrm{U}-\mathrm{O}_{\mathrm{ax}} \\
\mathrm{U}-\mathrm{O}_{\mathrm{eq} 1} \\
\mathrm{U}-\mathrm{O}_{\mathrm{eq} 2}\end{array}$ & $\begin{array}{l}2.00 \\
2.29 \\
2.51\end{array}$ & $\begin{array}{l}1.80 \\
2.29 \\
2.51\end{array}$ & $\begin{array}{l}0.0150 \\
0.0057 \\
0.0070\end{array}$ \\
\hline $\begin{array}{l}\text { Amorphous silica gel, } 0.5 \mathrm{mg} \mathrm{U}(\mathrm{VI}) \mathrm{kg}^{-1} \\
\text { solid, } \mathrm{pH} \sim 4{ }^{27} 5 \text { (Outer sphere) }\end{array}$ & $\begin{array}{l}\mathrm{U}-\mathrm{O}_{\mathrm{ax}} \\
\mathrm{U}-\mathrm{O}_{\mathrm{eq}} \\
\mathrm{U}-\mathrm{Si}\end{array}$ & $\begin{array}{c}2.0 \\
2.26 \\
0.50\end{array}$ & $\begin{array}{l}1.80 \\
2.29 \\
2.72\end{array}$ & $\begin{array}{l}0.0013 \\
0.0035 \\
0.0034\end{array}$ \\
\hline $\begin{array}{l}\text { Vermiculite, } 1.1 \mathrm{mM} \mathrm{U}(\mathrm{VI}), \mathrm{pH} \sim 2.5^{33} \\
\text { (Outer sphere) }\end{array}$ & $\begin{array}{l}\mathrm{U}-\mathrm{O}_{\mathrm{ax}} \\
\mathrm{U}-\mathrm{O}_{\mathrm{eq}}\end{array}$ & $\begin{array}{l}2.69 \\
3.52\end{array}$ & $\begin{array}{l}1.77 \\
2.43\end{array}$ & $\begin{array}{l}0.0034 \\
0.0090\end{array}$ \\
\hline $\begin{array}{l}\text { Vermiculite, } 3.3 \mu \mathrm{M} \mathrm{U}(\mathrm{VI}), \mathrm{pH} \sim 6-7^{33} \\
\text { (Outer sphere) }\end{array}$ & $\begin{array}{c}\mathrm{U}-\mathrm{O}_{\mathrm{ax}} \\
\mathrm{U}-\mathrm{O}_{\mathrm{eq} 1} \\
\mathrm{U}-\mathrm{O}_{\mathrm{eq} 2} \\
\mathrm{U}-\mathrm{U}\end{array}$ & $\begin{array}{l}2.23 \\
3.09 \\
1.02 \\
0.63\end{array}$ & $\begin{array}{l}1.80 \\
2.28 \\
2.48 \\
3.88\end{array}$ & $\begin{array}{l}0.0032 \\
0.0115 \\
0.0023 \\
0.0023\end{array}$ \\
\hline U co-precipitate with $\mathrm{Fe}(\mathrm{III})$ oxide $^{28}$ & $\begin{array}{l}\mathrm{U}-\mathrm{O} \\
\mathrm{U}-\mathrm{O} \\
\mathrm{U}-\mathrm{Fe}\end{array}$ & $\begin{array}{l}2.21 \\
2.36 \\
3.19\end{array}$ & $\begin{array}{l}1.40 \\
2.10 \\
1.12\end{array}$ & $\begin{array}{l}0.002 \\
0.007 \\
0.004\end{array}$ \\
\hline
\end{tabular}




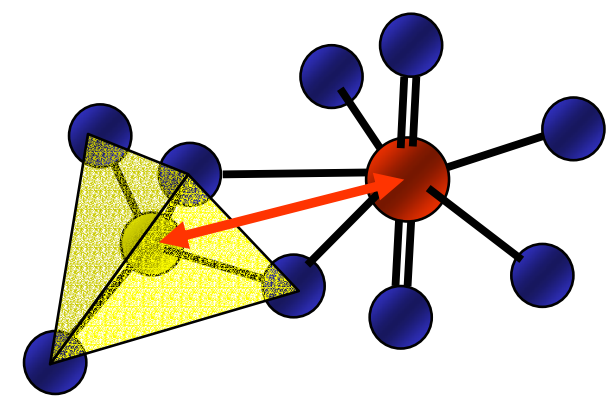

In all published U-EXAFS literature on uranyl sorption to silica gels, the U-Si distance is $\sim 2.71 \AA$ (red arrow), and has been interpreted as "edge sharing".

Hence, short U-Si distances WITHOUT the presence of long radial distances are a common signature for sorption.

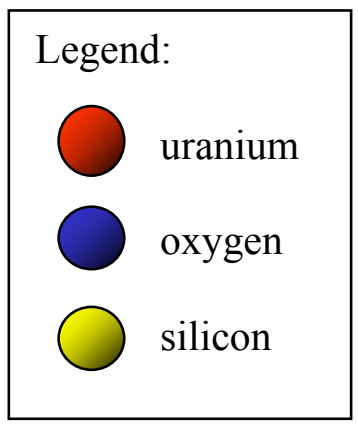

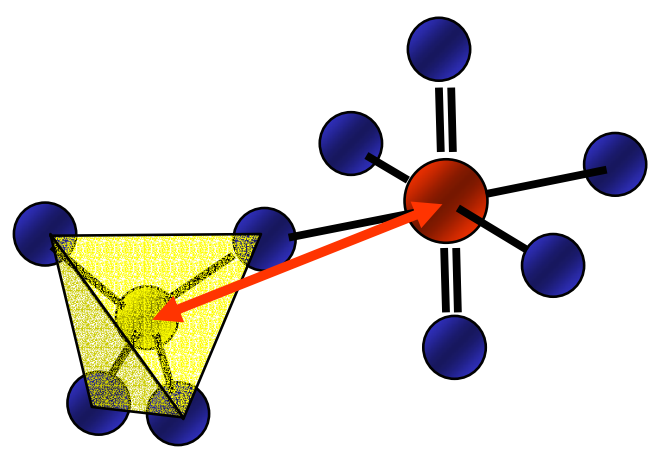

In published U-EXAFS literature on uranyl silicates, the U-Si distance is $\sim 3.7 \AA$ (red arrow) indicative of "corner sharing" or near $\sim 3.2 \AA$, which is indicative of edge sharing (not shown).

For polymeric uranyl species, long U-Si distances are a signature for structural incorporation of $U$ (i.e., longer bonds are required for a lattice arrangement as opposed to a sorption-type (i.e., amorphous) environment.

Figure 2-4 Pictorial representation of U(VI) edge and corner sharing with silica tetrahedra.

uptake of $\mathrm{U}$ from highly acidic solutions that are precipitating zeolites indicate that the $\mathrm{U}$ is in dimeric cavities of the zeolites as hydrated forms such as $\left[\mathrm{UO}_{2}(\mathrm{OH})_{4}\right]^{2-47}$

Other U XAFS-based characterization studies that were designed to precipitate zeolites in the presence of micro M levels of U(VI) have been conducted. ${ }^{48}$ These studies indicated that the U that precipitated during the formation of the zeolite (specifically, sodalite) was present in multiple forms such as uranyl oxide/oxide hydrates and silicates in addition to some uranate (as opposed to strictly uranyl) forms of $\mathrm{U}(\mathrm{VI})$. Corner-sharing behavior between the $\mathrm{O}$ atoms associated directly with $\mathrm{U}$ and tetrahedral $\mathrm{Si}$ was also observed. 
WSRC-TR-2004-00016, REVISION 0

\subsubsection{U(VI) Precipitate Forms}

In contrast to sorbed U(VI) species on surfaces and U that is co-precipitated in other host mineral forms, U-XAFS and X-ray diffraction crystallographic studies have shown that uranyl silicate minerals such as soddyite $\left[\left(\mathrm{UO}_{2}\right)_{2} \mathrm{SiO}_{4} \cdot 2 \mathrm{H}_{2} \mathrm{O}\right], \mathrm{Na}_{4}\left(\mathrm{UO}_{2}\right)_{2} \mathrm{Si}_{4} \mathrm{O}_{10} \cdot 4 \mathrm{H}_{2} \mathrm{O}_{(\mathrm{s})}$, Na-boltwoodite $\left[\mathrm{Na}_{2}\left(\mathrm{UO}_{2}\right)_{2}\left(\mathrm{SiO}_{3} \mathrm{OH}\right)_{2} \cdot 1.5 \mathrm{H}_{2} \mathrm{O}\right]$ and Na-weeksite $\left[\mathrm{Na}_{2}\left(\mathrm{UO}_{2}\right)_{2}\left(\mathrm{Si}_{5} \mathrm{O}_{13}\right)_{6} \cdot 3 \mathrm{H}_{2} \mathrm{O}\right]$ possess predominantly corner-sharing behavior as opposed to edge-sharing behavior between $\mathrm{U}$ polyhedra and silica tetrahedra as shown in Figure 2-4 and Figure 2-5. ${ }^{11,49,50}$ Studies of U(VI) in borosilicate glasses indicate that U(VI) typically contains two axial $\mathrm{O}$ atoms at a distance of 1.77 to $1.85 \AA$ and four to five O's at a distance of 2.21 to $2.25 \AA$. $^{13}$

\subsubsection{Uranium Speciation in HLW Systems}

Little if any experimental XAFS work has been done with dissolved, sorbed U or precipitated species under conditions relevant to that of HLW solutions, such as in highly caustic, high ionic strength aqueous solutions. However, the hexavalent U(VI) is probably the predominant oxidation state of $U$ in HLW salt solutions. Uranium-XAFS studies have been performed to study the structure of high levels of dissolved U(VI) species under simulated caustic solutions [in 3.5 M tetramethyl ammonium, which was used as a counterion to suppress precipitation of $\mathrm{U}(\mathrm{VI})]^{20}$ and of solid phase U in real HLW samples. ${ }^{51}$ These XAFS studies identified that the most common U(VI) complexes in caustic solutions are likely to be the monomeric $\mathrm{UO}_{2}(\mathrm{OH})_{4}{ }^{2-}$ and $\mathrm{UO}_{2}(\mathrm{OH})_{5}{ }^{-}$species. Our recent studies with $\mathrm{U}$ in real HLW sludge indicate that about $95 \%$ of the sludge $U$ exists in the hexavalent $U(V I)$ form whereas about $5 \%$ of the $U$ is metallic. ${ }^{51}$

Recently, more information about the fundamental interaction between $U$ solid formation and NAS in HLW salt solutions has become available. ${ }^{52}$ For example, laboratory precipitation studies with solutions containing low levels of dissolved $\mathrm{Na}^{+}(0.02 \mathrm{M})$ in addition to roughly 0.1 $\mathrm{M}$ each of dissolved U(VI) and Si favor the formation of crystalline uranyl silicate solids whereas similar studies using higher levels of dissolved $\mathrm{Na}^{+}(5.6 \mathrm{M})$ favored the formation of clarkeite $\mathrm{Na}_{4}\left(\mathrm{UO}_{2}\right)\left(\mathrm{O}, \mathrm{OH}_{2}\right)_{2(\mathrm{~s})}$, which is a partially hydrated form of sodium diuranate $\left(\mathrm{Na}_{2} \mathrm{U}_{2} \mathrm{O}_{7}\right)_{(\mathrm{s}) .}{ }^{53}$ Although these studies characterized the crystalline forms of $\mathrm{U}$ in these samples, they did not characterize any amorphous forms of $U$ silicates or oxides in these samples.

\subsection{Experimental Objectives}

The primary objective of this research was to obtain information on speciation of $U$ in U-rich aluminosilicate scale from the $2 \mathrm{H}$ Evaporator using XAFS and other more traditional characterization techniques, such as wet chemical analyses of sample digestions, electron microscopy imaging and XRD analyses. We used XAFS techniques to obtain information on the average local structural speciation of the $\mathrm{U}$ such as $\mathrm{CN}$, geometry, near and next nearest neighbor environment of the target metal. In contrast to XRD data, which provide information on the crystalline phases, XAFS information describes both crystalline and amorphous U phases. 
WSRC-TR-2004-00016, REVISION 0

Uranium bearing silicate minerals are characterized by $\mathrm{U}$ cross-linked by corner sharing $\mathrm{SiO}_{4}$ tetrahedra as well as some edge sharing $\mathrm{SiO}_{4}$ tetrahedra. The local environment of the $\mathrm{U}$ in the structures below has 5 equatorial $\mathrm{O}$ atoms.

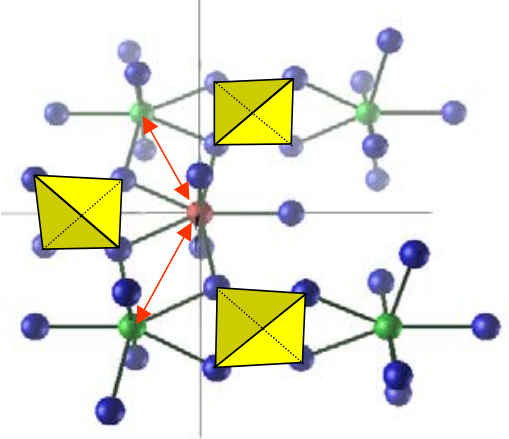

Soddyite: one edge sharing, two corner sharing $\mathrm{SiO}_{4}$ tetrahedra

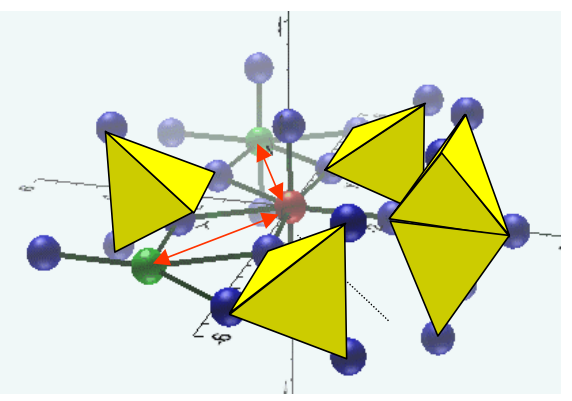

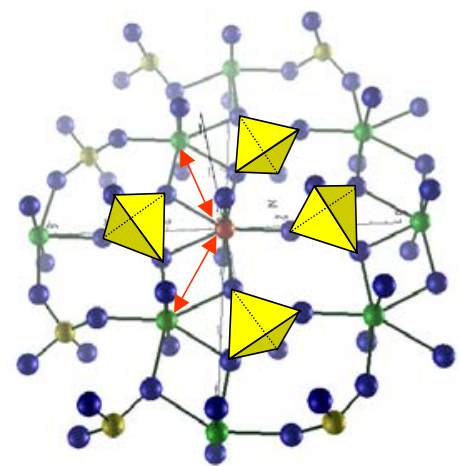

Boltwoodite: one edge sharing, three corner sharing $\mathrm{SiO}_{4}$ tetrahedra

Legend:

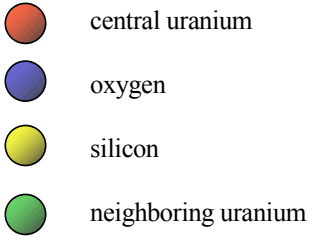

Weeksite: one edge sharing, four corner sharing $\mathrm{SiO}_{4}$ tetrahedra

Figure 2-5 Examples of uranyl silicate structures. Red arrows denote radial U-U distances that can be obtained using crystallographic and XAFS analyses. 


\subsection{MATERIALS AND EXPERIMENTAL METHODS}

\subsection{Elemental and Isotopic Characterization of Sample}

In 2000, 2H-Evaporator solids were obtained from the sidewall of the $2 \mathrm{H}$-Evaporator prior to the addition of the depleted uranyl carbonate and nitric acid cleaning solutions and archived. ${ }^{1}$ The archived solids had a "salt and pepper" appearance and the lighter colored particles had a reddish-yellow tint. Sub-samples of the scale were characterized by the SRTC Analytical Development Section (ADS) using XRD and scanning electron microscopy (SEM). Two onegram quantities of the sample were digested (as duplicates) in nitric acid by ADS and the two digest solutions were then analyzed for radiochemical and other elemental contents. The ADS analyzed the digest solutions using inductively coupled plasma mass spectroscopy (ICP-MS) for the actinides and technetium and inductively coupled plasma atomic emission spectroscopy (ICP-AES) for the major and trace metals (both radioactive and stable). The digest solutions were also analyzed for $\mathrm{Pu}$ isotopics using $\mathrm{Pu}$-triphenyltrifluoroacetone ( $\mathrm{Pu}$-TTA) extraction and scintillation analysis (for ${ }^{239 / 240} \mathrm{Pu}$ and ${ }^{238} \mathrm{Pu}$ ). Gamma spectroscopy was conducted by ADS using the digest solutions to determine the levels of cesium-137 $\left({ }^{137} \mathrm{Cs}\right)$, antimony-125 $\left({ }^{125} \mathrm{Sb}\right)$, and americium-241 $\left({ }^{241} \mathrm{Am}\right)$. Strontium-90 $\left({ }^{90} \mathrm{Sr}\right)$ was determined by radiochemical separation and quantification by scintillation counting.
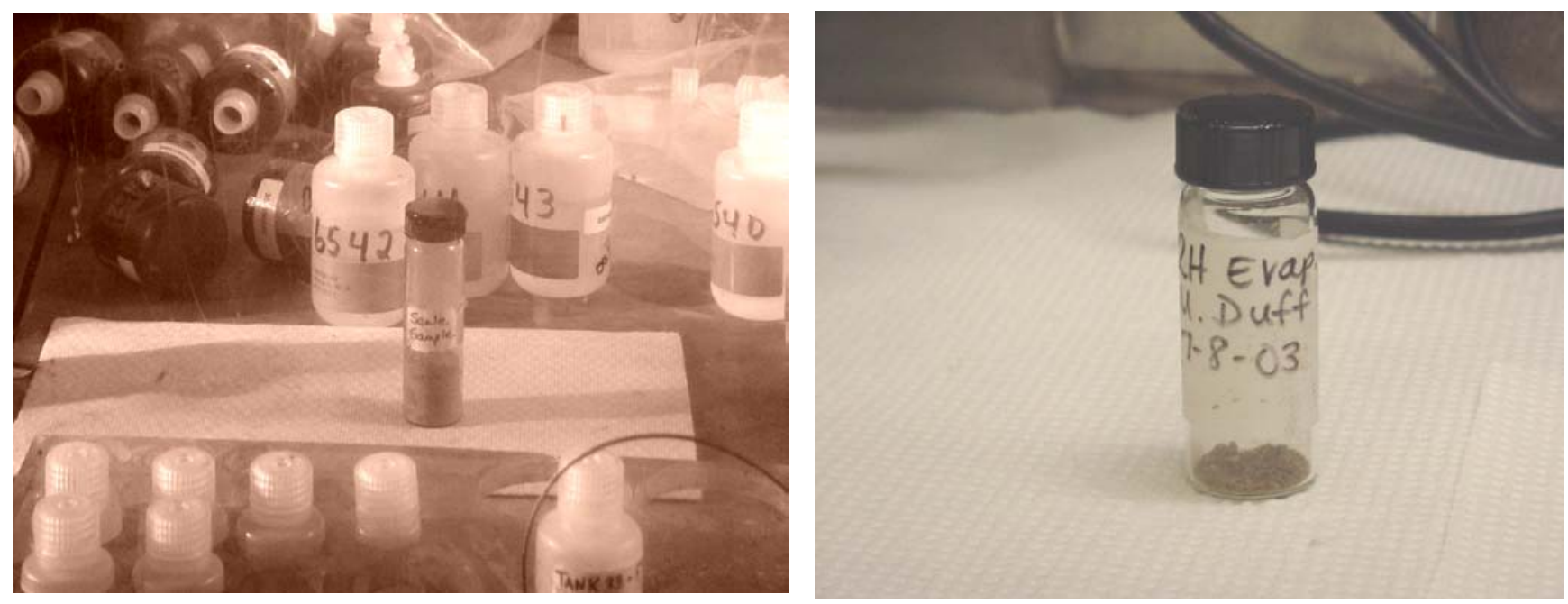

Figure 3-1 Pictures of the archived $2 \mathrm{H}$ scale material used in this study.

\subsection{XRD Data Collection and SEM Imaging}

Two solid phase samples were characterized by XRD using a Siemens D500 automated scanning diffractometer with $\mathrm{CuK} \alpha$ radiation. An internal standard was added so that the relative 
proportions of crystalline solids and amorphous silica could be estimated. These analyses required overnight XRD spectral acquisition. The diffractometer is equipped with a $1^{\circ}$ degree divergence slit and divergence anti-scatter slit in addition to a $1^{\circ}$ degree divergence beam antiscatter slit and $2^{\circ}$ degree diffracted-beam Soller slit. The diffractometer uses a curved pyrolytic graphite monochromator with a $0.015^{\circ}$ receiving slit and a sodium iodide scintillation detector. The samples were mounted on a glass slide using colloidon to promote the preparation of a flat and evenly dispersed sample on the glass slide. The data were collected from 5 to $70^{\circ}$ at 2 -theta, and a one-second dwell time for every $0.02^{\circ}$. For these analyses, the most intense reflection from some compounds can be detected at $0.5 \mathrm{wt} \%$.

A Cambridge S250 Scanning Electron Microscope in containment for examination of radioactive samples was used to examine and image the scale sub samples.

\subsection{Sample Preparation for XAFS}

Several sub-samples $(70 \mathrm{mg})$ of the solids were placed in specially-designed primary sample holders for XAFS analyses as shown in Figure 3-2 and Figure 3-3. These sample holders were placed in an aluminum box with kapton film window, which allowed XAFS spectra to be acquired through these windows. The height of the samples in the window location of the box is manipulated electronically by a motor controlled stage (as shown in Figure 3-4) that was sealed in a large motor-controlled aluminum metal box (shown in Figure 3-5). The assembly of the aluminum box and sample stage took place at Argonne National Laboratory (ANL) in the Actinide Facility.

\subsection{EXAFS Data Collection}

The XAFS data were collected on Sector 12 at the Advanced Photon Source (APS, Argonne National Laboratory, Argonne, IL) using a bending magnet beamline setup (Figure 3-6 and Figure 3-7). Uranium-XAFS data were collected at the $\mathrm{U} \mathrm{L}_{3}$-edge (17,166 eV) on air-dried scale sample at room temperature. The XAFS data were collected in fluorescence and transmission mode using an unfocussed X-ray beam. A fixed-exit Si (111) monochromator consisting of a cryo-cooled crystal was used to select the energy of the X-ray beam. A detailed description of the beamline design is provided in Beno et al. (2001). ${ }^{54}$

Ion chambers were used to collect incident, transmission and reference signals. Gas ratios for the data collection in $I o$ were $100 \%$ argon. A multielement fluorescence detector was used to collect fluorescence X-rays. The monochromator energy was maximized using a piezo stack feedback energy stabilization system, with a settling time of 0.3 seconds per change in monochromatic energy. An X-ray beam size of 2 by $2 \mathrm{~mm}^{2}$ was used. Energy calibration was done using a yttrium (Y) foil (K-edge, 17,038 eV). 


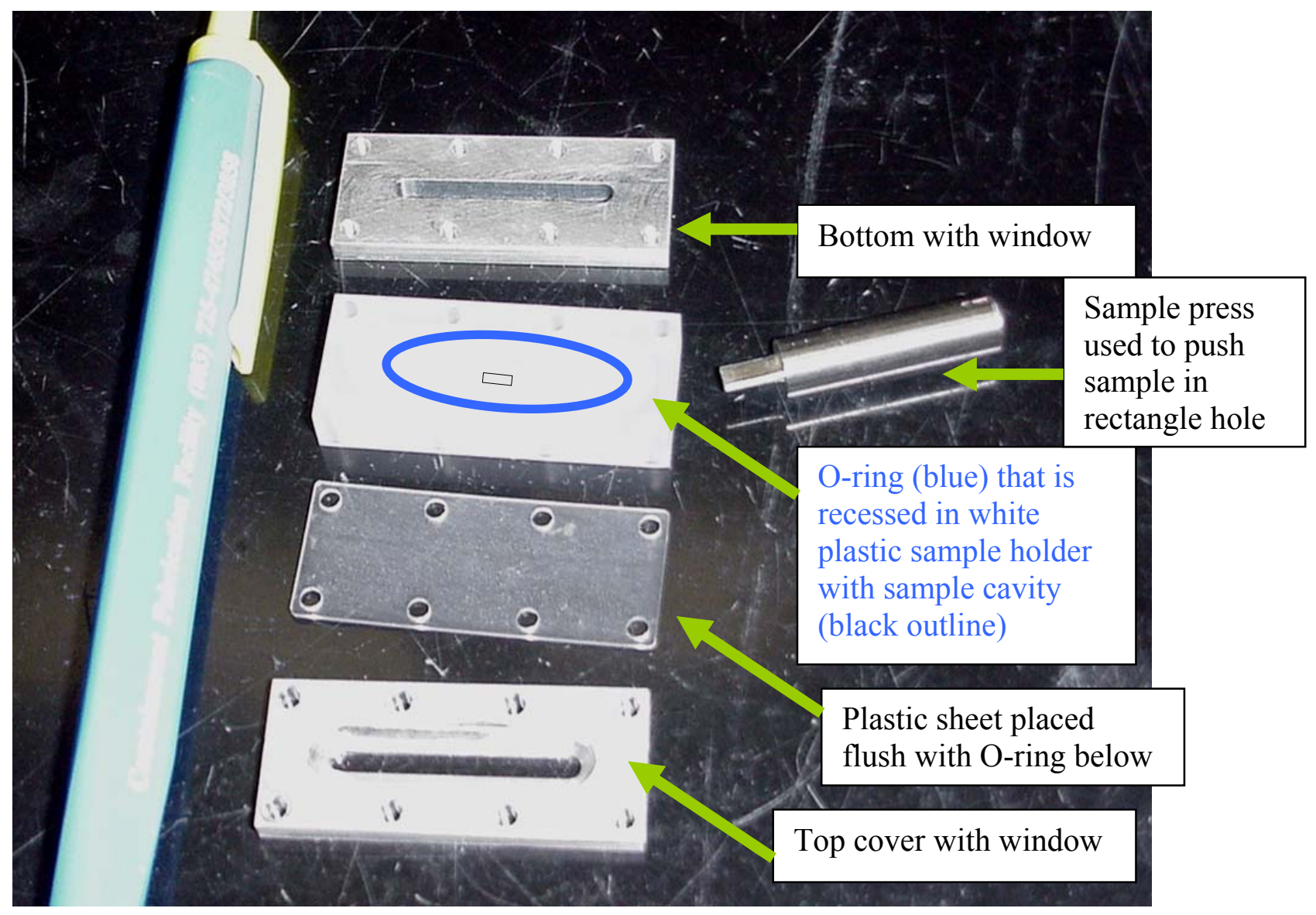

Figure 3-2 Image of the components used in the primary sample holders. Once assembled with eight metal screws, these primary holders are placed on a motorized stage, which is then placed in a sealed metal box. The sealed metal box also serves as additional containment for the samples during handling and analyses.

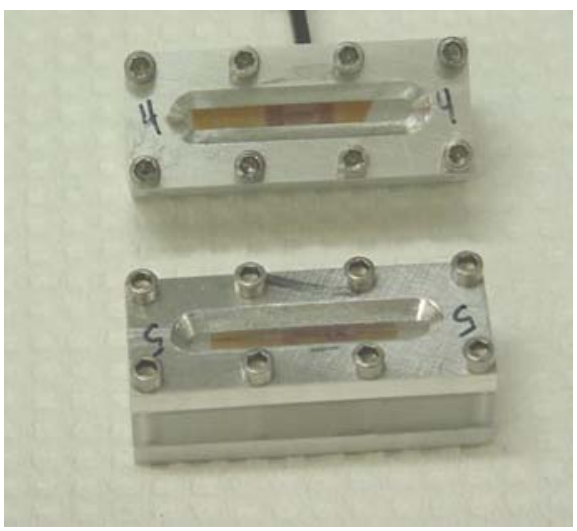

Figure 3-3 Image of two of the intact primary sample holders that were used to contain the $2 \mathrm{H}$ Evaporator scale. 


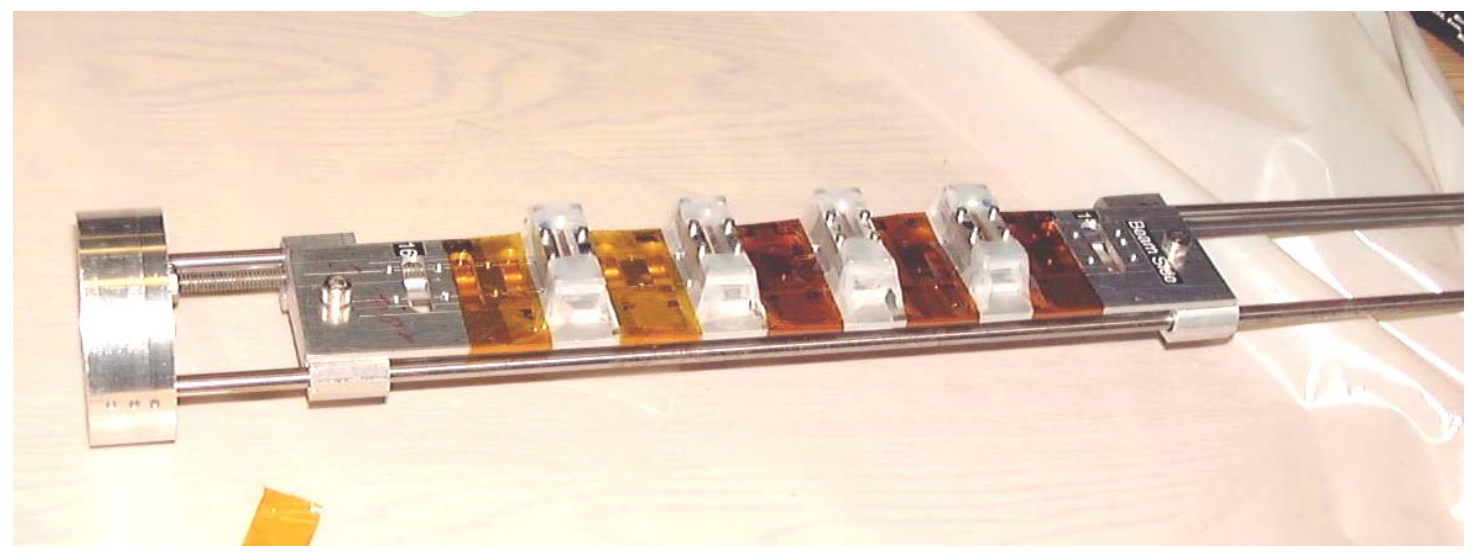

Figure 3-4 Picture of the sample stage that is placed inside a large aluminum box. The stage is motor controlled. It permits the controlled raising or lowering of the stage to allow one to move from sample to sample without having to breach the containment.

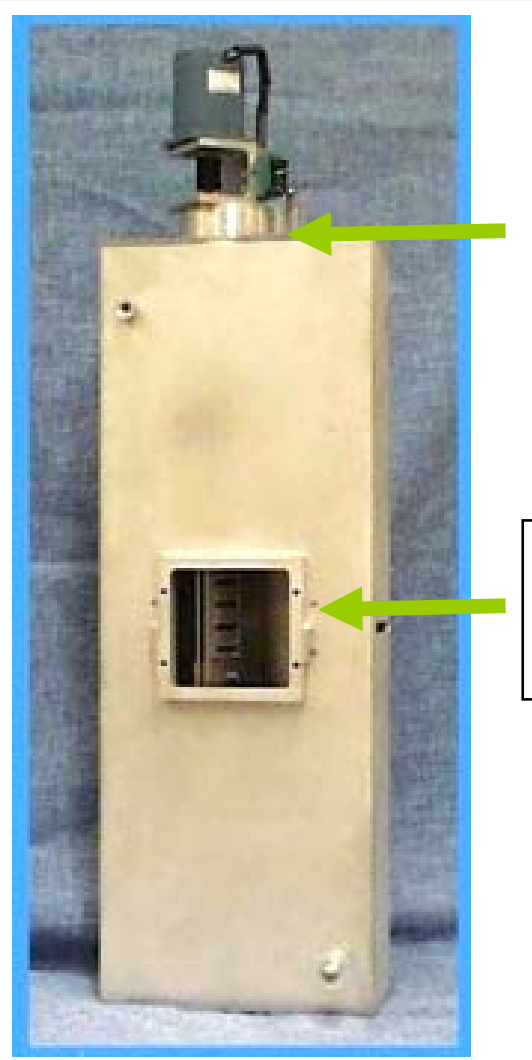

Stage

motor

control

Kapton film window, showing motorized stage with mounted samples

Figure 3-5 Picture of the aluminum metal box that was used to contain the 2H-Evaporator scale samples in their primary containment and to hold the motor-controlled sample stage. 


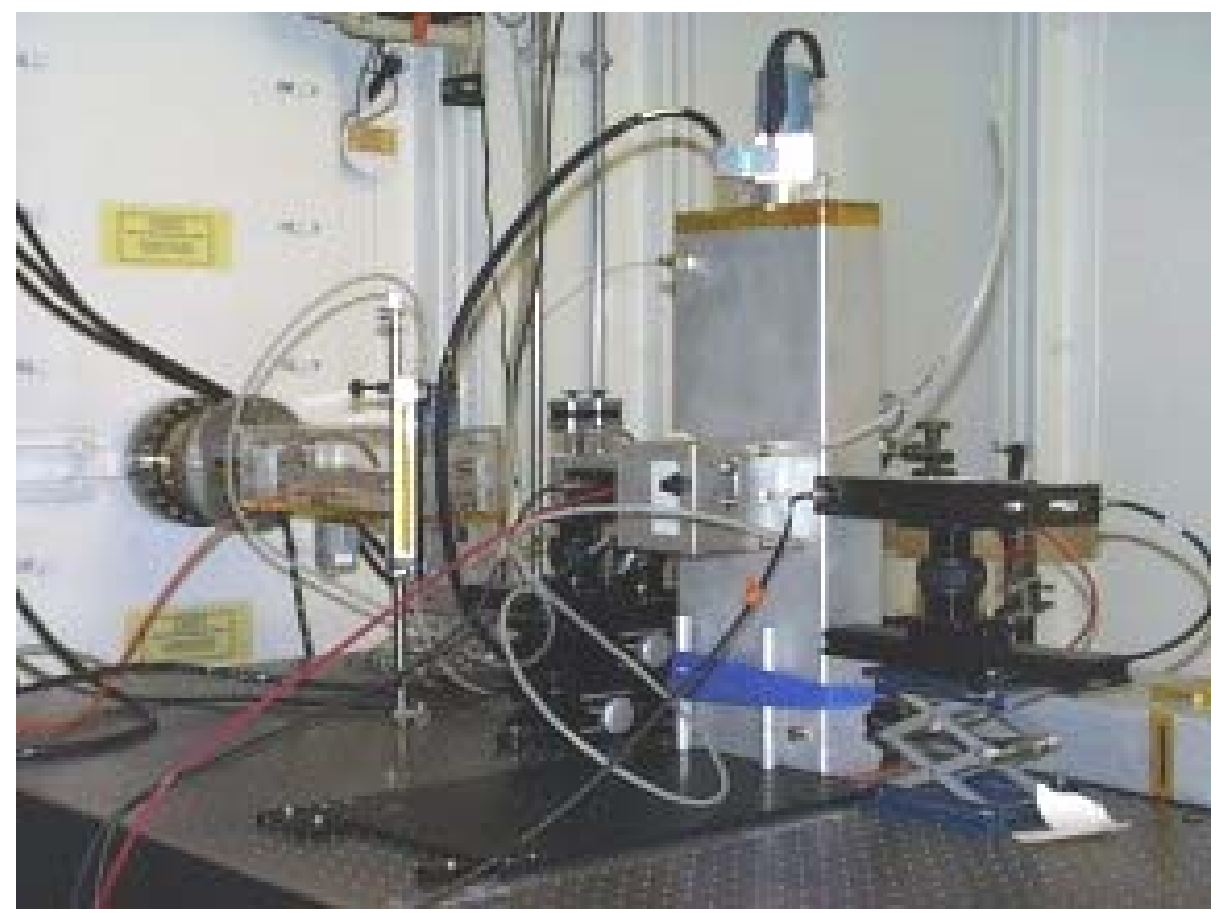

Figure 3-6 The beam line endstation setup at Bending Magnet 12 at the Advanced Photon Source. The multielement detector that was used is not shown in this picture. The aluminum metal sample box that contained the radioactive samples is shown and positioned between two ion chambers (Io and It).

\subsection{EXAFS Data Analyses}

In simple terms, chi data (the plot of the wavevector in reciprocal space) show the oscillatory component (with both constructive and destructive interferences) of the atoms in the neighbor environment of the element of interest. The chi data represent part of the photoelectron wave that can be defined by the EXAFS equation. ${ }^{30,31,55}$ The EXAFS equation is shown in a highly simplified form below (see list of definitions for explanation of equation terms):

$$
\operatorname{Chi}(\mathrm{k})=\frac{\mathrm{F}(\mathrm{k}) * \mathrm{~N} * \mathrm{~S}}{\mathrm{k} * \mathrm{R}^{2}} S_{0}{ }^{2} e^{\left(-2 * \mathrm{k}^{3} \sigma^{2}\right)} \sin [2 * \mathrm{k} * \mathrm{R}+\delta(\mathrm{K})] .
$$

The background contribution to the EXAFS spectra was removed using an algorithm (AUTOBK) developed by Newville et al. (1993), which minimizes R-space values in low $k$ space. Each chi data set was read into the WINXAS analysis package. ${ }^{56,57}$ Replicate scans were co-added to improve signal-to-noise $(\mathrm{S} / \mathrm{N})$. The U-XAFS spectra were analyzed from 2.7 to 12.5 


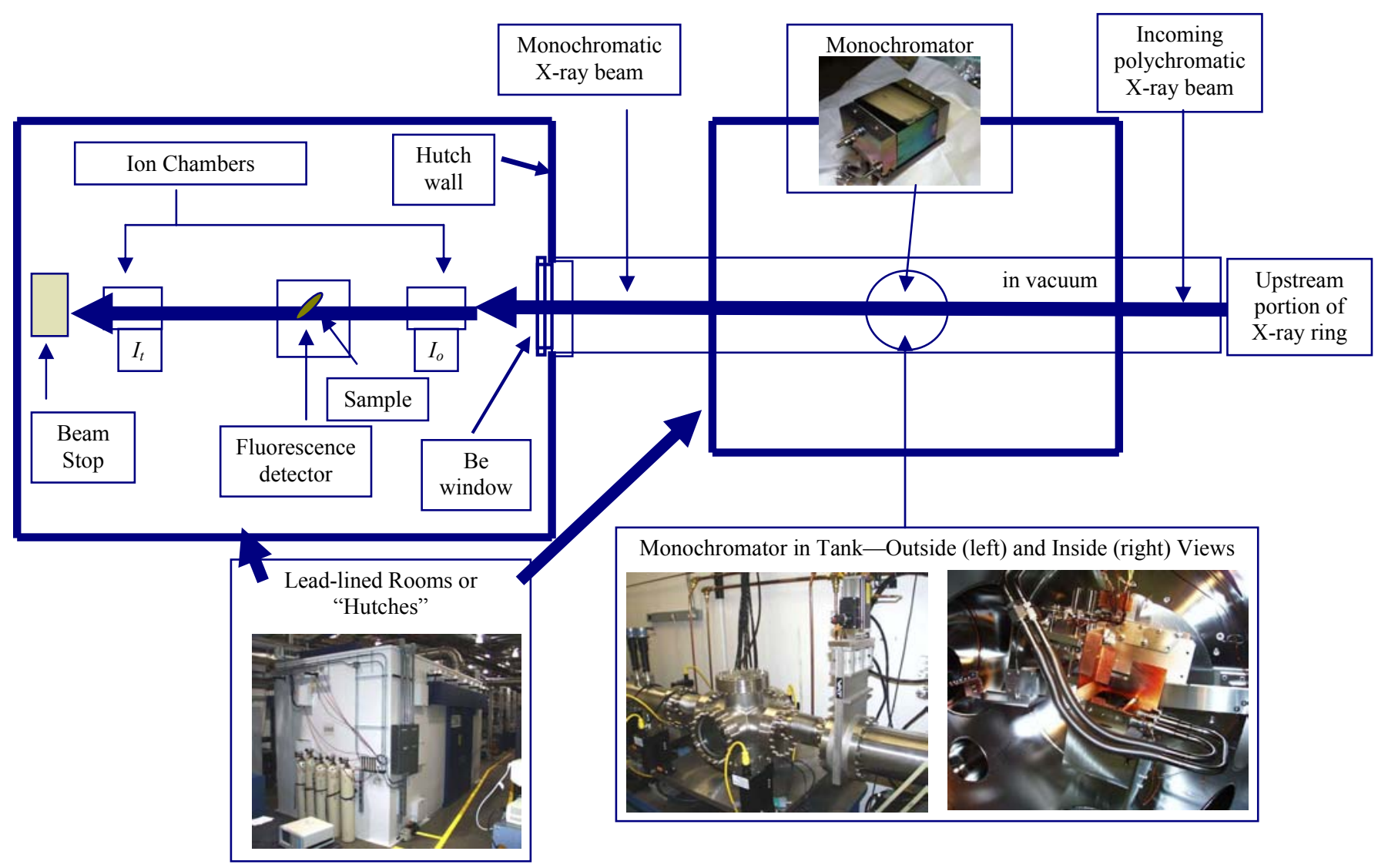

Figure 3-7 Diagram of BM-12 at the Advanced Photon Source (not drawn to scale). Bending magnet and other upstream portions of the X-ray ring not shown.

$\AA^{-1}$. The chi data were $k^{2}$-weighted and Fourier-transformed (FT) to yield R-space or Radial Distribution Function (RDF) plots. ${ }^{58}$ Simulated EXAFS spectra were also generated based on the documented crystallographic properties for uranyl silicate and oxyhydroxide solids using ab initio based theory, which involved FEFF 7.2 a program created by researchers at the Univ. of Washington. $^{59,60,61,62,63,64}$ Model fits for U were performed in R-space. 


\subsection{RESULTS}

\subsection{Elemental and Isotopic Characterization of $2 \mathrm{H}$-Evaporator Scale after Sample Digestion}

The results of the sample digests for the archived scale sample are listed in Table 4-1, 4-2 and 43. The elemental constituents in the sample consist mainly of percent levels of $\mathrm{Si}, \mathrm{Al}$, U with lesser quantities of calcium $(\mathrm{Ca})$, iron $(\mathrm{Fe})$, zirconium $(\mathrm{Zr})$, sulfur $(\mathrm{S})$, tin $(\mathrm{Sn})$ and nickel $(\mathrm{Ni})$ as listed in Table 4-1. The level of U determined by ICP-AES was about $4.6 \%$, which is slightly lower than that obtained by ICP-MS - to be discussed. The sample error in the ICP-MS analyses is within the range of the U concentration obtained from the ICP-AES analyses. Table 4-2 contains counting data for some of the commonly occurring radionuclides observed in the SRS tank farm HLW.

Table 4-1 Average characterization data for ICP-AES analyses of the digested $2 \mathrm{H}$ Evaporator scale (based on single analyses of duplicate sample digestions). Values are $\pm 10 \%$ for all elements, with the exception of $\pm 12 \%$ for $\mathrm{Si}$. Sodium was not analyzed for.

\section{Element Concentration $\left(\mathrm{mg} \mathrm{kg}^{-1}\right)$}

$\begin{array}{cc}\text { Aluminum } & 95400 \\ \text { Calcium } & 1175 \\ \text { Chromium } & 264 \\ \text { Copper } & 45 \\ \text { Iron } & 5960 \\ \text { Manganese } & 64 \\ \text { Nickel } & 1185 \\ \text { Sulfur } & 1907 \\ \text { Silicon } & 58700 \\ \text { Tin } & 1693 \\ \text { Strontium } & 297 \\ \text { Titanium } & 28 \\ \text { Zirconium } & 3723 \\ \text { Uranium } & 46050\end{array}$


Table 4-2 Average radiochemical data for analyses of the digested 2H-Evaporator scale (based on single analyses of duplicate sample digestions). The $\mathrm{Pu}$ analyses were performed using the $\mathrm{Pu}$-TTA extraction method with alpha radiometric counting. Strontium-90 was analyzed using scintillation analyses and the remaining isotopes were analyzed using gamma spectroscopy.

$\begin{array}{cccc}\text { Element } & \text { Isotope } & \begin{array}{c}\text { Average } \\ \text { Activity } \\ \left.\text { (dpm g }^{-1}\right)\end{array} & \begin{array}{c}\text { Average } \\ \text { Uncertainty } \\ (\%)\end{array} \\ \mathrm{Pu} & 238 & 5.14 \mathrm{E}+08 & 2.63 \\ \mathrm{Pu} & 239 / 240 & 1.69 \mathrm{E}+07 & 10.0 \\ \mathrm{Sb} & 125 & 4.56 \mathrm{E}+07 & 2.15 \\ \mathrm{Cs} & 137 & 3.55 \mathrm{E}+08 & 1.37 \\ \mathrm{Am} & 241 & 3.90 \mathrm{E}+06 & 15.6 \\ \mathrm{Sr} & 90 & 3.92 \mathrm{E}+08 & 14.5\end{array}$

Table 4-3 Average characterization data for ICP-MS analyses of the digested 2H-Evaporator scale (based on single analyses of duplicate sample digestions). The calculated isotopic abundance for the ${ }^{235} \mathrm{U} /{ }^{(235+238)} \mathrm{U}$ was $2.22 \%$. The large error in the ${ }^{238} \mathrm{U}$ is due to error from the sample and not the instrument.

\section{Isotope Mass}

234 (assumed to be mostly Thorium) 235 (assumed to be mostly U)

237 (assumed to be mostly Neptunium)

238 (assumed to be mostly U)

239 (assumed to be mostly $\mathrm{Pu}$ )

\section{Concentration ( $\mathrm{mg} \mathrm{kg}^{-1}$ )}

$$
\begin{aligned}
142 & \pm 46.6 \\
1275 & \pm 420 \\
397 & \pm 103 \\
55940 & \pm 18700 \\
355 & \pm 115
\end{aligned}
$$


WSRC-TR-2004-00016, REVISION 0

\subsection{Characterization of 2H-Evaporator Scale using XRD and SEM Microscopy Techniques}

The solid phase samples were analyzed using powder XRD and SEM imaging techniques. The XRD data for the two replicate scale samples are shown in Figure 4-1. These spectra indicate that the primary crystalline phases in the scale are the sodium aluminosilicates (such as cancrinite and sodalite) and the partially hydrated form of sodium diuranate $\left(\mathrm{Na}_{2} \mathrm{U}_{2} \mathrm{O}_{7}\right)$ called clarkeite $\left[\mathrm{Na}_{4}\left(\mathrm{UO}_{2}\right)\left(\mathrm{O}, \mathrm{OH}_{2}\right)_{2(\mathrm{~s})}\right]$. The presence of clarkeite in the scale is not unexpected. It has a similar structure to that of sodium diuranate and therefore is difficult to assign because these two materials have similar diffraction patterns. The baseline for these spectra is not flat. The broad peak that comprises the baseline between 15 and 30 two-theta may be due to an amorphous phase such as silica gel. The amount of amorphous phase relative to that of the Ucontaining clarkeite phase could not be estimated. In contrast, this broad peak in the baseline of the spectra was not observed in previously published XRD spectra for $2 \mathrm{H}$-evaporator scale deposits, which were taken by Wilmarth et al. (2000) from the evaporator wall as shown in Figure 4-2. ${ }^{65}$ Hence, the XRD data for these two scale samples indicate that there may be solid phase heterogeneity within the evaporator scale.

Sodium diuranate was found to be the dominant crystalline $U$ phase in the scale during the Wilmarth et al. (2000) study. Clarkeite was not previously identified in the spectra (shown in Figure 4-2) that were previously acquired (in the year 2000) because clarkeite has only recently been added to our XRD pattern database. When we compare these older spectra and with that of clarkeite as in Figure 4-2A, we obtain a better fit than that for sodium diuranate (as in Figure 42B). The centroids of the diffraction peaks for clarkeite are more representative of the highest intensities of the peaks in the scale spectra. Clarkeite and sodium diuranate ${ }^{66,67}$ have extremely similar structures (i.e., they are isostructural), which accounts for some of confusion over nomenclature and structural assignments. The main difference between these two phases is the amount of hydration. Sodium diuranate is not hydrated.

Two SEM images of the scale are shown in Figure 4-3 and Figure 4-4. Both of these figures show three types of commonly observed particles in the scale. The first particle consists of mainly $\mathrm{U}$ with minor $\mathrm{Na}, \mathrm{Al}$, and $\mathrm{Si}$ as shown. The morphology of these particles resembles that of particles that were identified in U-saturated HLW simulants by XRD to consist of clarkeite. ${ }^{3}$ The second particle type is rich in $\mathrm{Na}, \mathrm{Al}$ and $\mathrm{Si}$ and contains minor $\mathrm{U}$. The third particle type was not as abundant as the first two types. It typically contained metals such as $\mathrm{Ni}, \mathrm{Cu}, \mathrm{Fe}$ or $\mathrm{Hg}$ (and mixtures thereof). 
A)

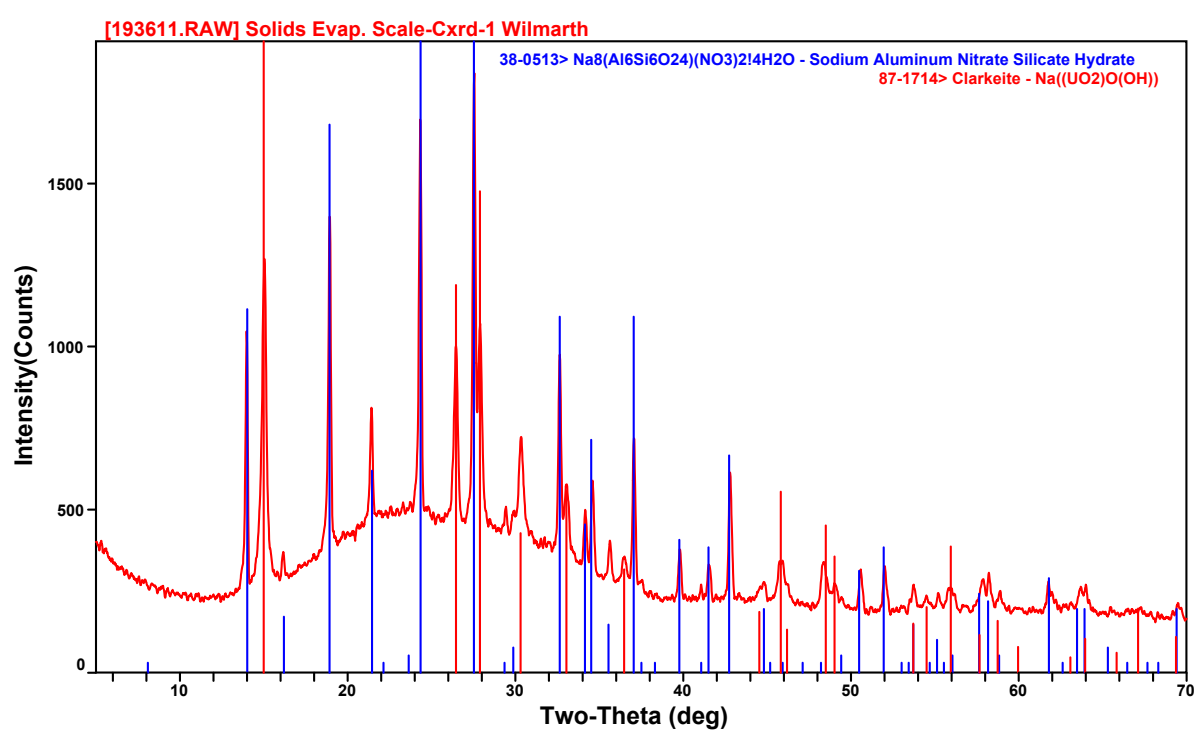

B)

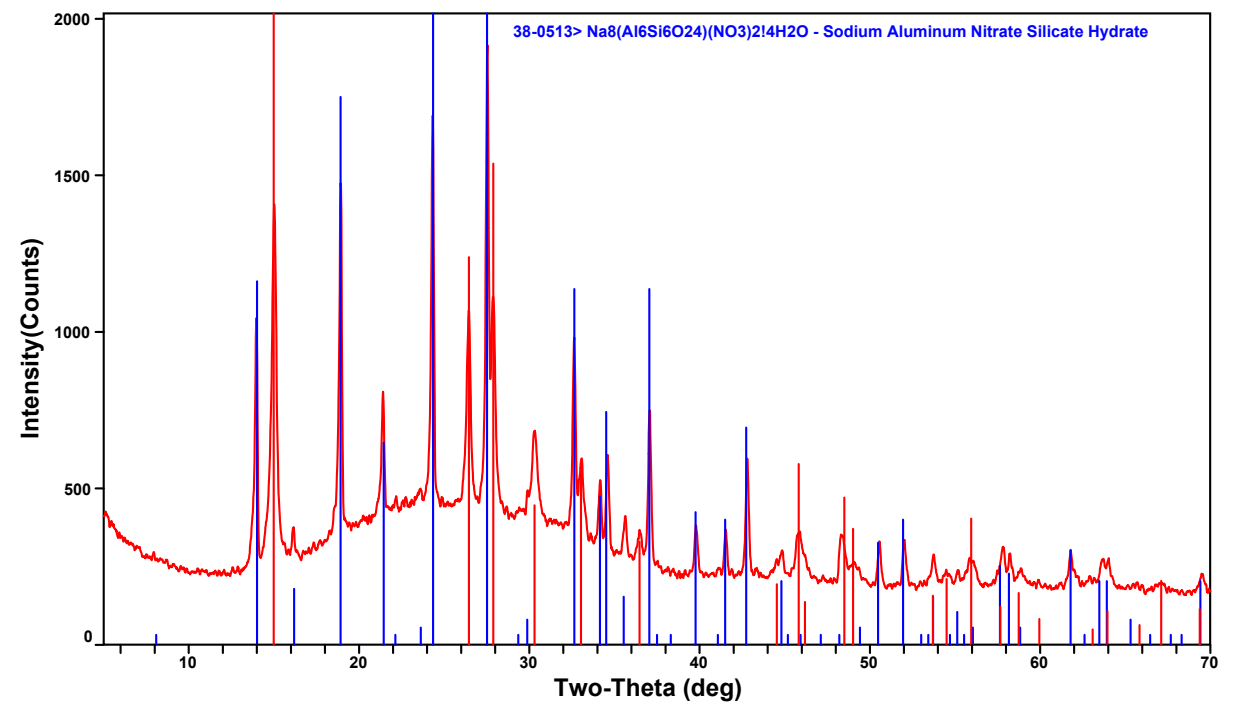

Figure 4-1 XRD characterization data for the two replicate samples [A) and B)] of the archived $2 \mathrm{H}$-evaporator scale. 
A)

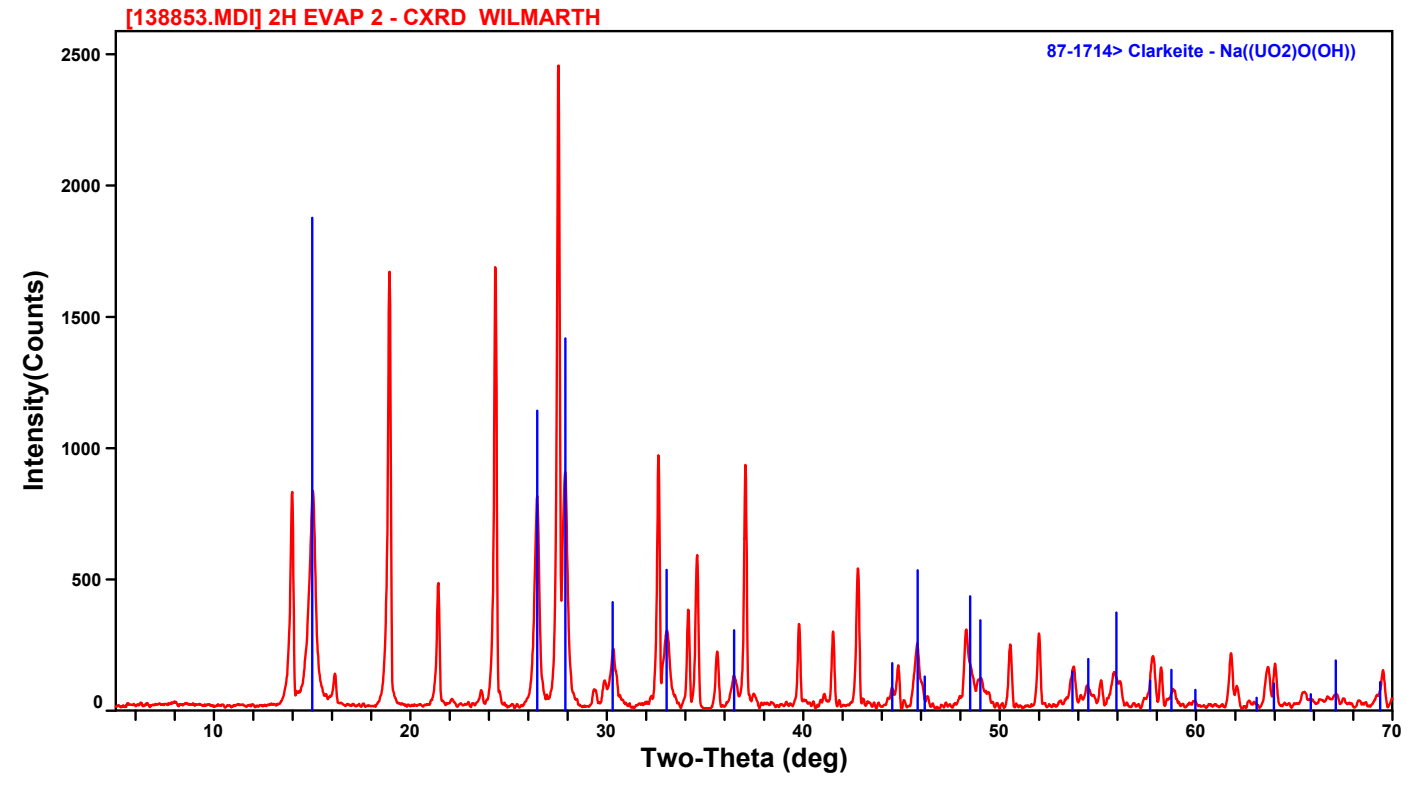

B)

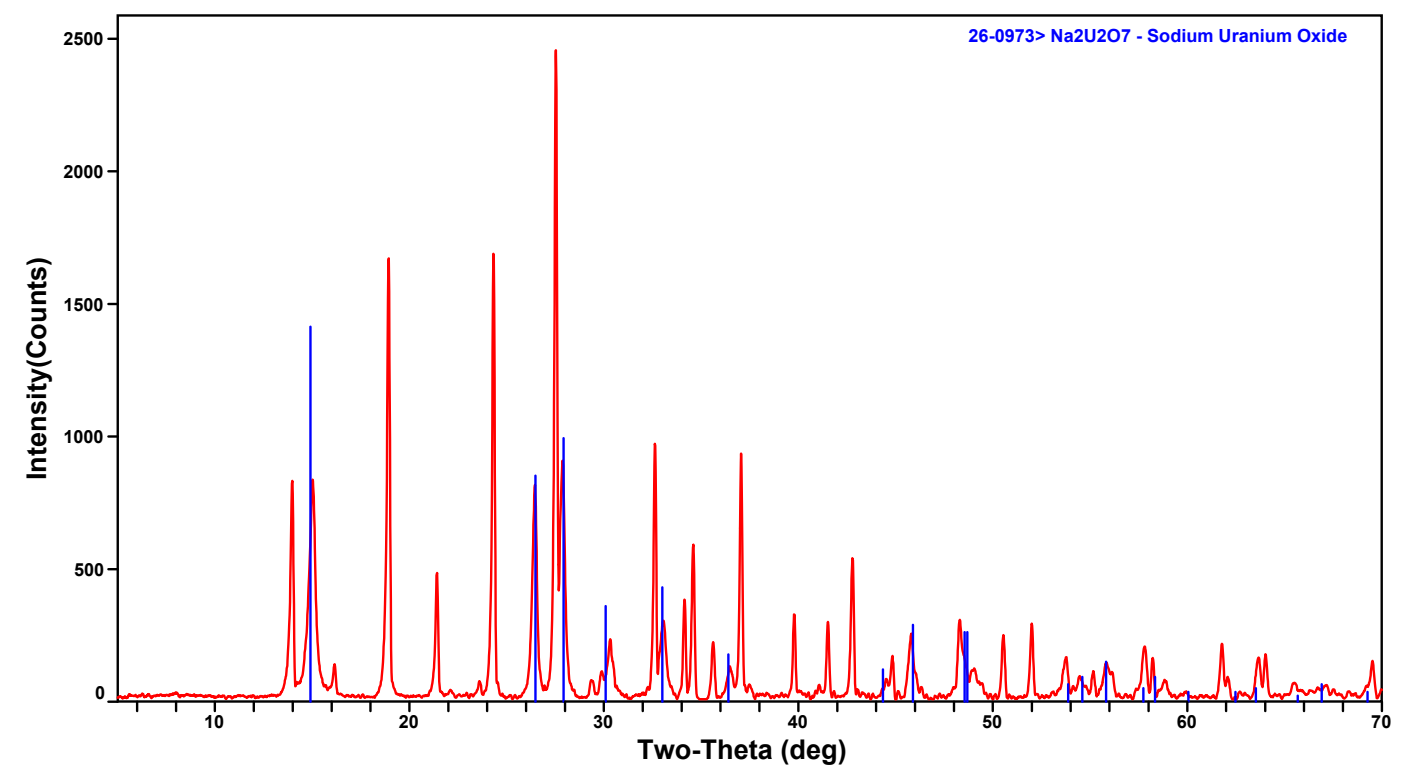

Figure 4-2 XRD characterization data for the 2H-Evaporator scale from Wilmarth et al. 2000. ${ }^{65}$ These spectra show the improved fit that is obtained using A) clarkeite instead of B) sodium diuranate. 


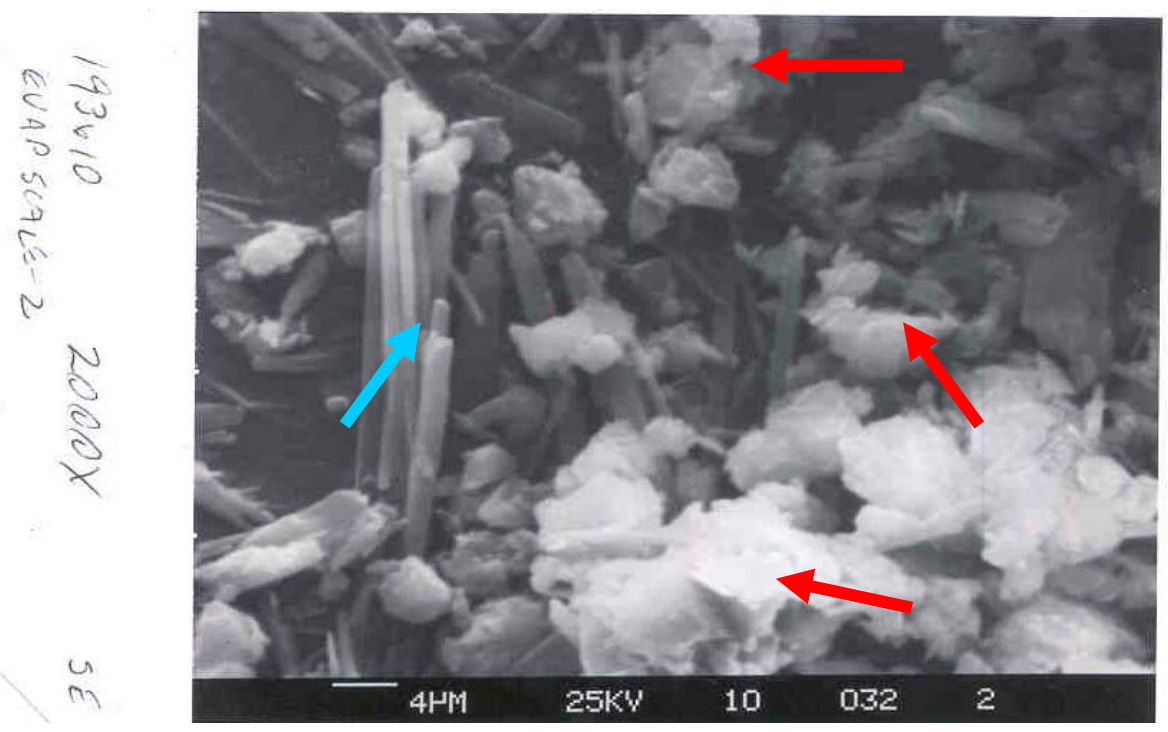

Figure 4-3 SEM photomicrograph of 2H-Evaporator scale. Red arrows denote U-rich areas with minor $\mathrm{Na}, \mathrm{Al}$ and $\mathrm{Si}$. The blue arrow denotes what appears to be a cancrinite needle. This region has minor $\mathrm{U}$ and high levels of $\mathrm{Na}, \mathrm{Al}$ and $\mathrm{Si}$.

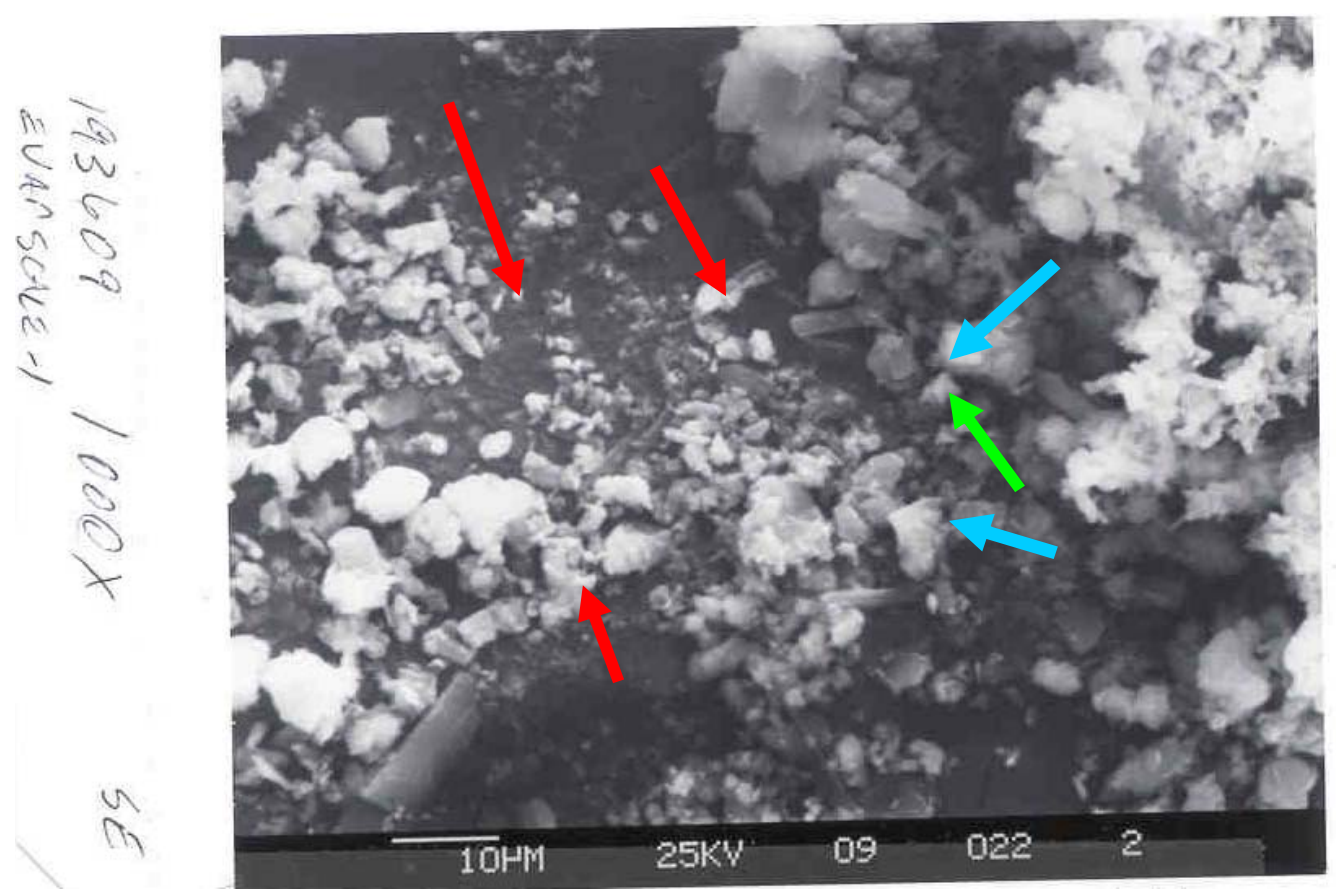

Figure 4-4 SEM photomicrograph of 2H-Evaporator scale. Red arrows denote U-rich areas with minor $\mathrm{Na}, \mathrm{Al}$ and $\mathrm{Si}$. Blue arrows denote regions with minor $\mathrm{U}$ and high levels of $\mathrm{Na}, \mathrm{Al}$ and $\mathrm{Si}$. The green arrow shows a region that is rich in $\mathrm{Fe}$ and $\mathrm{Cu}$. 


\subsubsection{Uranium XANES Data for the 2H-Evaporator Scale}

The U-XANES data provide information on the average oxidation state of the $U$ present and some information on the local structural environment. The energy (in eV) of the $\mathrm{U} \mathrm{L}_{3}$ absorption edge is used to define the oxidation state. The spectra are shown in Figure 4-5. Based on comparison with a $\mathrm{Y}$ foil reference and previous XANES data for U(VI) species, these are representative of $\mathrm{U}(\mathrm{VI})$.

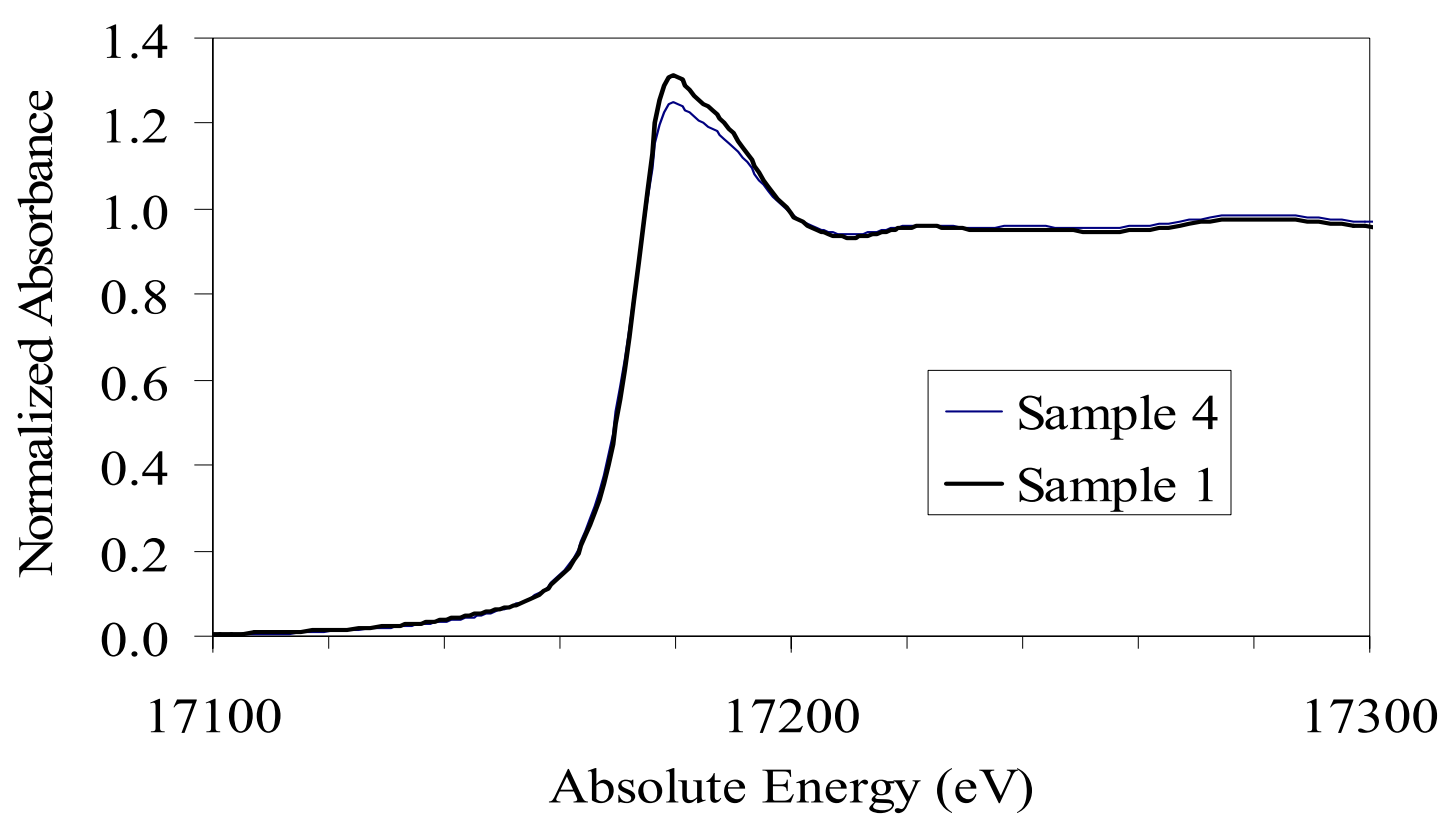

Figure 4-5 Normalized XANES spectra for $U$ in the two scale samples.

\subsubsection{Uranium Chi Data for the 2H-Evaporator Scale}

The $k^{2}$-weighted chi spectra for the $\mathrm{U}$ in two sub samples of the $2 \mathrm{H}$-Evaporator scale are shown in Figure 4-6. These spectra were of excellent quality, which was mainly due to good beamline stability and to the high $U$ concentrations in the samples. The highest quality spectra were from sample 4, which had a higher $U$ concentration than the other sample 1 . The chi data for $U$ in the two replicate scale samples indicate there are light and heavy atom backscatterers as evidenced by the presence of a large amplitude signals at low and high $\mathrm{k}$. For comparison, the $k^{2}$-weighted chi spectra for the $U$ in the $2 \mathrm{H}$-Evaporator scale and the $\mathrm{U}$ in the co-precipitated sodalite material (after washing with DI water and concentrated carbonate solution) are shown in Figure 4-7.

However, the spectra for the scale and washed U-NAS samples are quite different in that they are not in phase with each other and that the amplitudes of the oscillations do not compare (Figure 4-7). Comparison of the chi spectra for the $U$ in the scale with that of simulated clarkeite and sodium boltwoodite XAFS spectra (in Figure 4-8 and Figure 4-9) reveal that the scale U XAFS spectra does not contain a large amount of either of these solids. 


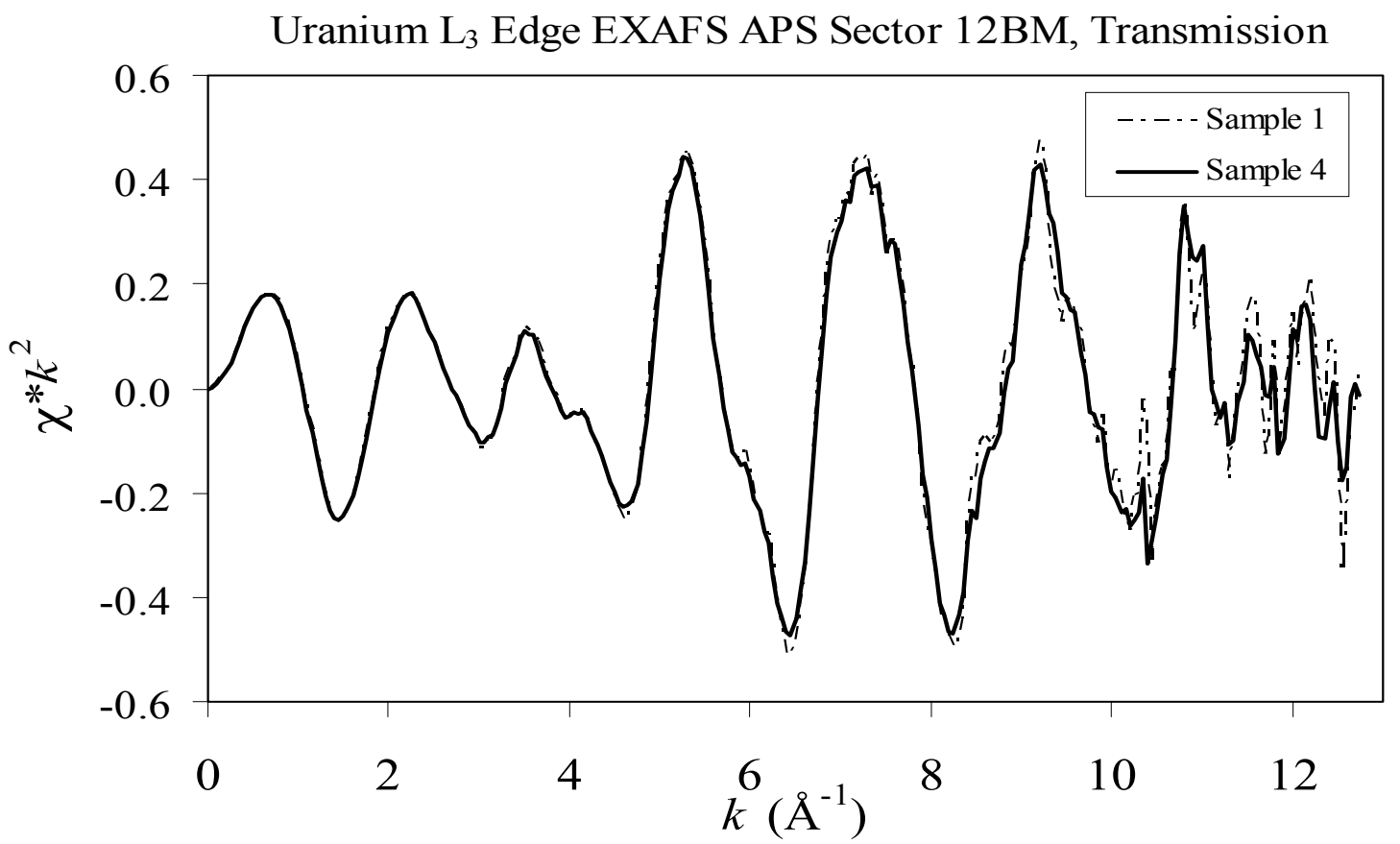

Figure 4-6 The $k^{2}$-weighted chi data (the plot of the wavevector in reciprocal space) for the $2 \mathrm{H}$ evaporator scale sample.

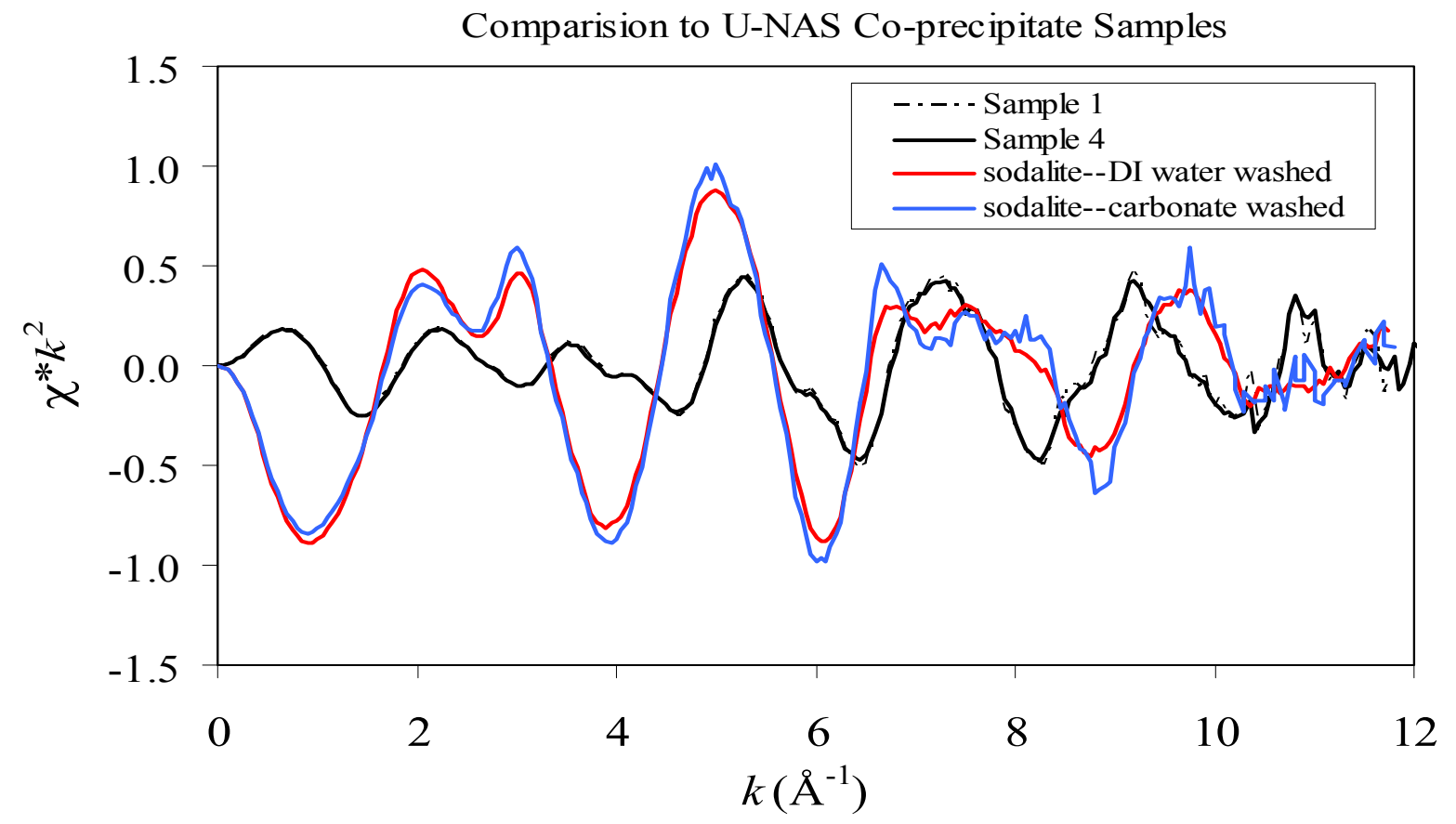

Figure 4-7 The $k^{2}$-weighted chi data (the plot of the wavevector in reciprocal space) for the $2 \mathrm{H}$ evaporator scale and the U-NAS co-precipitate samples from Duff, Hunter and Oji (2002). 


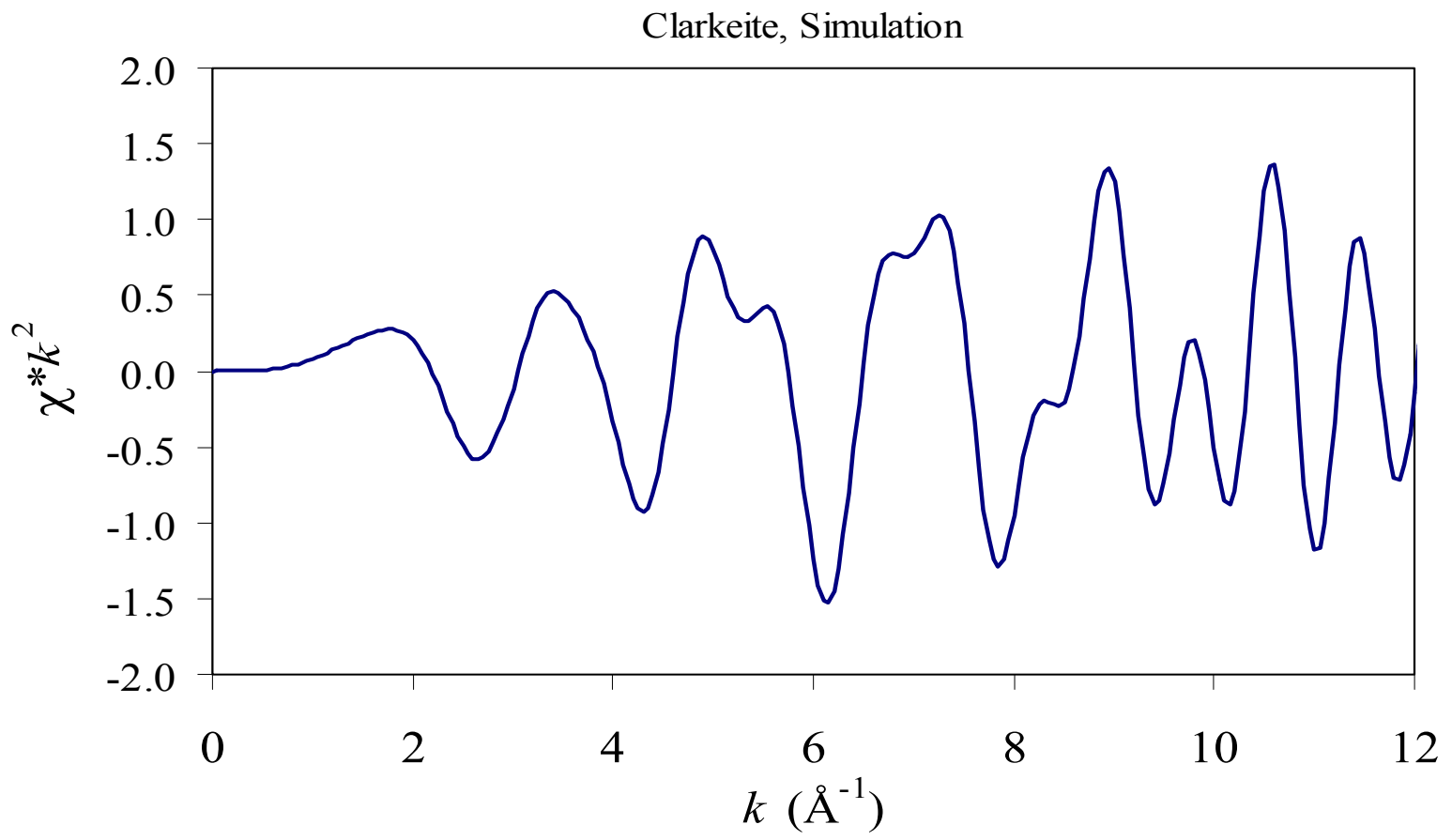

Figure 4-8 Simulation of $k^{2}$-weighted chi data for clarkeite for comparison.

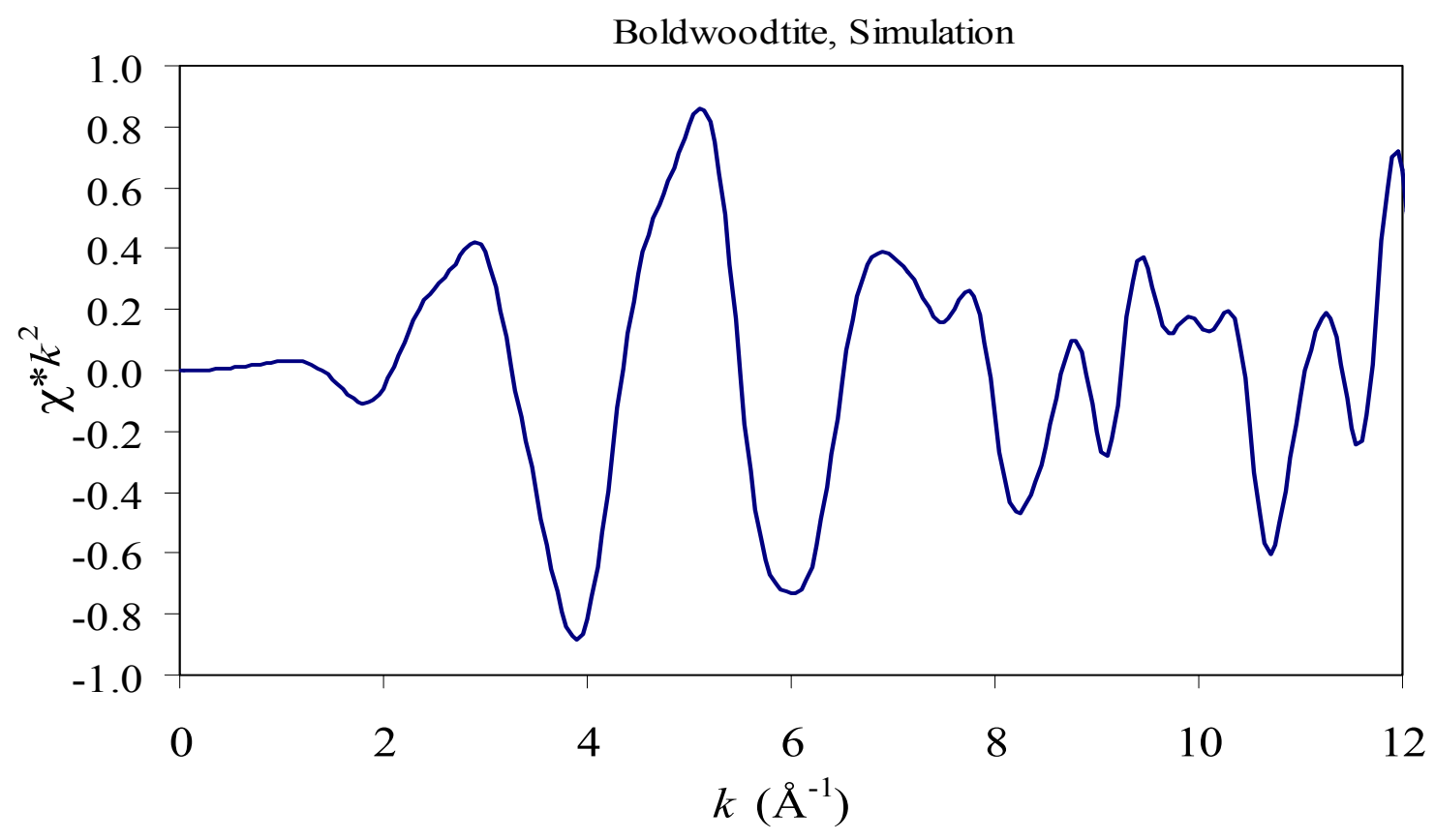

Figure 4-9 Simulation of $k^{2}$-weighted chi data for boltwoodite for comparison. 


\subsubsection{Uranium Fourier-Transformed Data for the 2H-Evaporator Scale}

The Fourier-Transformed (FT) data for the 2H-Evaporator scale samples are shown in Figure 4-10. There are significant peaks in the transforms at greater radial distances (i.e., outer shells) for the samples, suggesting that higher shell atoms are present.

The strongly defined peaks in the 3 to $4 \AA$ region are not characteristic of the uranyl oxide hydrate schoepite-suggesting that schoepite is probably not present in these scale materials. ${ }^{40}$ This is because schoepite has so many $U-U$ distances and due to destructive interference from so many U-U interactions, the FT spectra tend to be fairly structureless in the 3 to $4 \AA$ region.

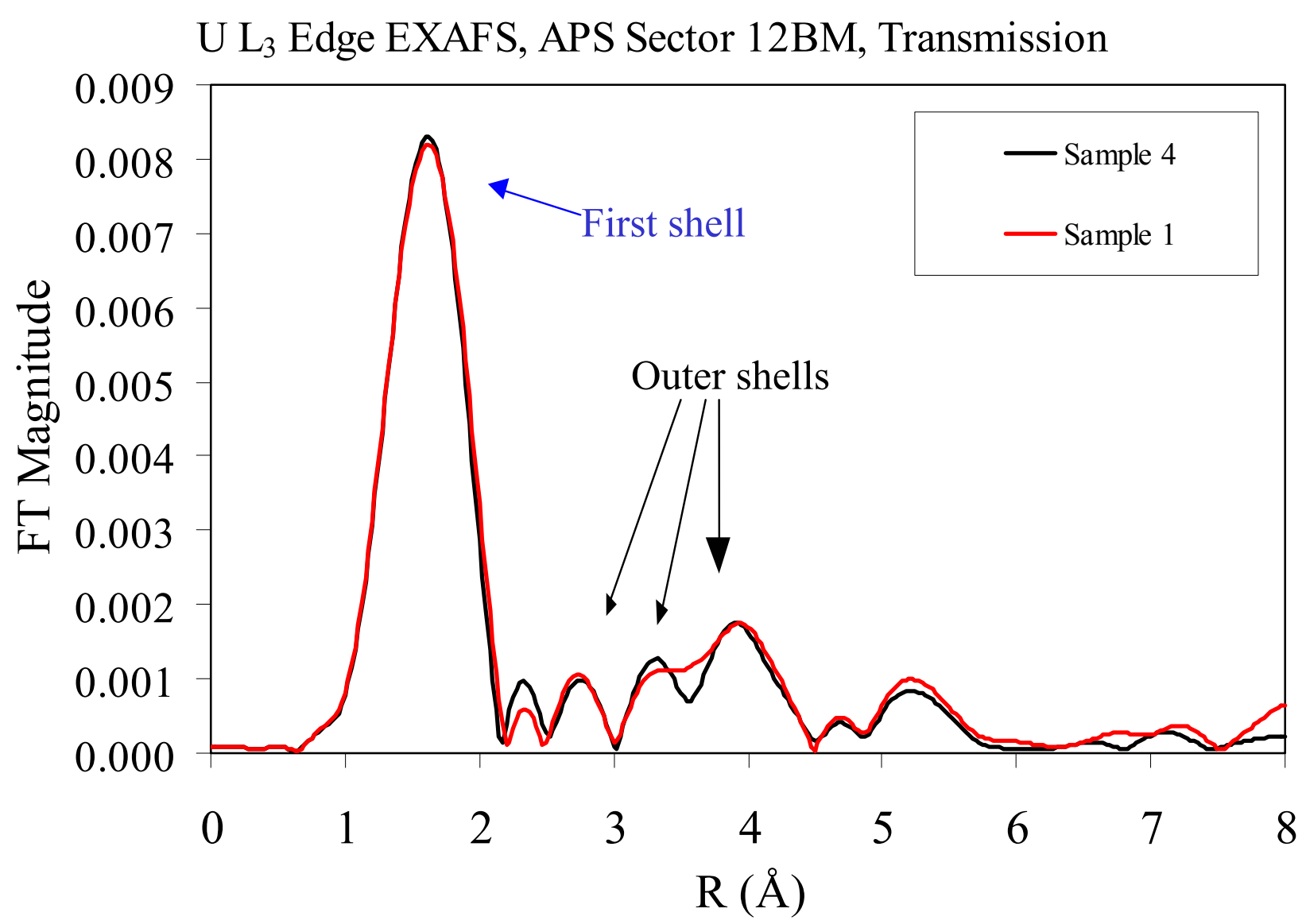

Figure 4-10 FT data for the archived 2H-Evaporator scale series samples - uncorrected for phase shift. 


\subsubsection{Uranium FT and Model Fit Data for the 2H-Evaporator Scale}

The FT data and corresponding first shell fit data for the first coordination shell of the $U$ in the 2H-Evaporator scale are shown in Figure 4-11. Data for sample 1 were nearly identical to sample 4 (data not shown, sample 1 contained roughly ten fold less $U$ than sample 4 ). The spectra for both of the samples indicate that the first coordination shell consists of a split shell that contains $\mathrm{O}$ atoms at two different distances $(1.85 \AA$ and $2.19 \AA)$. The first shell U-O distance at $1.85 \AA$ is longer than most axial U-O bonds, which are typically close to 1.75 to 1.80 $\AA$. However, this first shell U-O environment has radial U-O distances is indicative of uranyltype behavior as opposed to uranate-type behavior. ${ }^{49}$ More information on these two types of U(VI) bonding behaviors is shown in Figure 2-3. Clarkeite has a split first shell with two U-O radial distances of $1.89 \AA$ and six equatorial U-O distances of $2.30 \AA$. The axial U-O distance for clarkeite is considerably longer than $1.85 \AA$ and such a long distance is atypical for most uranyl forms of $U(V I)$. Clarkeite is best referred as a uranyl form of $U(V I)$ as opposed to a uranate form as illustrated in Figure 2-3. Our U-XAFS data for this material are not consistent with any documented $U$ phases.

The FT data and corresponding fit data for the higher shell regions of the $\mathrm{U}$ in the $2 \mathrm{H}$-evaporator scale are shown in Figure 4-12. The FT data for the outer shells (Figure 4-12) contains two Si atoms at a U-Si radial distance of $3.85 \AA$, which is a distance indicative of Si corner-sharing behavior with $\mathrm{U}$ polyhedra as previously discussed. [Due to their similar size, the presence of $\mathrm{Al}$ instead of $\mathrm{Si}$ is possible however Si provided a much better fit.] Three $\mathrm{U}$ atoms at a U-U radial distance of $4.13 \AA$ were also observed. The distances observed for the U-Si and U-U interactions a within the range typically observed for $U$ oxide hydrates and $U$ silicates.

Collectively, our data indicate an amorphous uranyl silicate phase or phases are present in this $2 \mathrm{H}$-evaporator scale sample. The first shell environment is similar to U(VI) in high temperature borosilicate glasses, however the outer shell structure is not consistent with $U$ in these glasses. ${ }^{13}$ This is because the U-XAFS analyses for these U-rich glasses did not contain higher shell atoms, such as $\mathrm{U}$ or Si. The first shell axial and equatorial U-O environment and U-Si outer shell environment of the $\mathrm{U}$ in the scale is most similar to that of a crystalline sodium $\mathrm{U}(\mathrm{VI})$ silicate that was synthesized in a Parr bomb at $230{ }^{\circ} \mathrm{C}$ for 2 days (crystalline structure shown in Figure 4-13). ${ }^{11}$ However, the U-U distance (at roughly $6 \AA$ ) in this material is much longer than what we observed for the U-U distance in the scale.

Furthermore, these U-U model fit data are not representative of uranate phases, which have much longer U-U radial distances [e.g., U-U at $6 \AA$ for a cobalt uranate, as cited in Farges et al. (1992)]. ${ }^{13}$ The peak in the FT between 5 to $6 \AA$ is unusual because it is highly visible. This distance is be \#yond the range that most XAFS fits are performed for U(VI) solids because it is too far away from the absorbing $U$ atom to fit quantitatively. This pronounced peak indicates that the U(VI) solid(s) present is highly structured. Although we did not detect uranate forms of $\mathrm{U}(\mathrm{VI})$, this peak may be due to a U-U interaction in a uranate-type solid. 
Sample 4: $\mathrm{U} \mathrm{L}_{3}$ Edge EXAFS APS Sector 12BM, Transmission

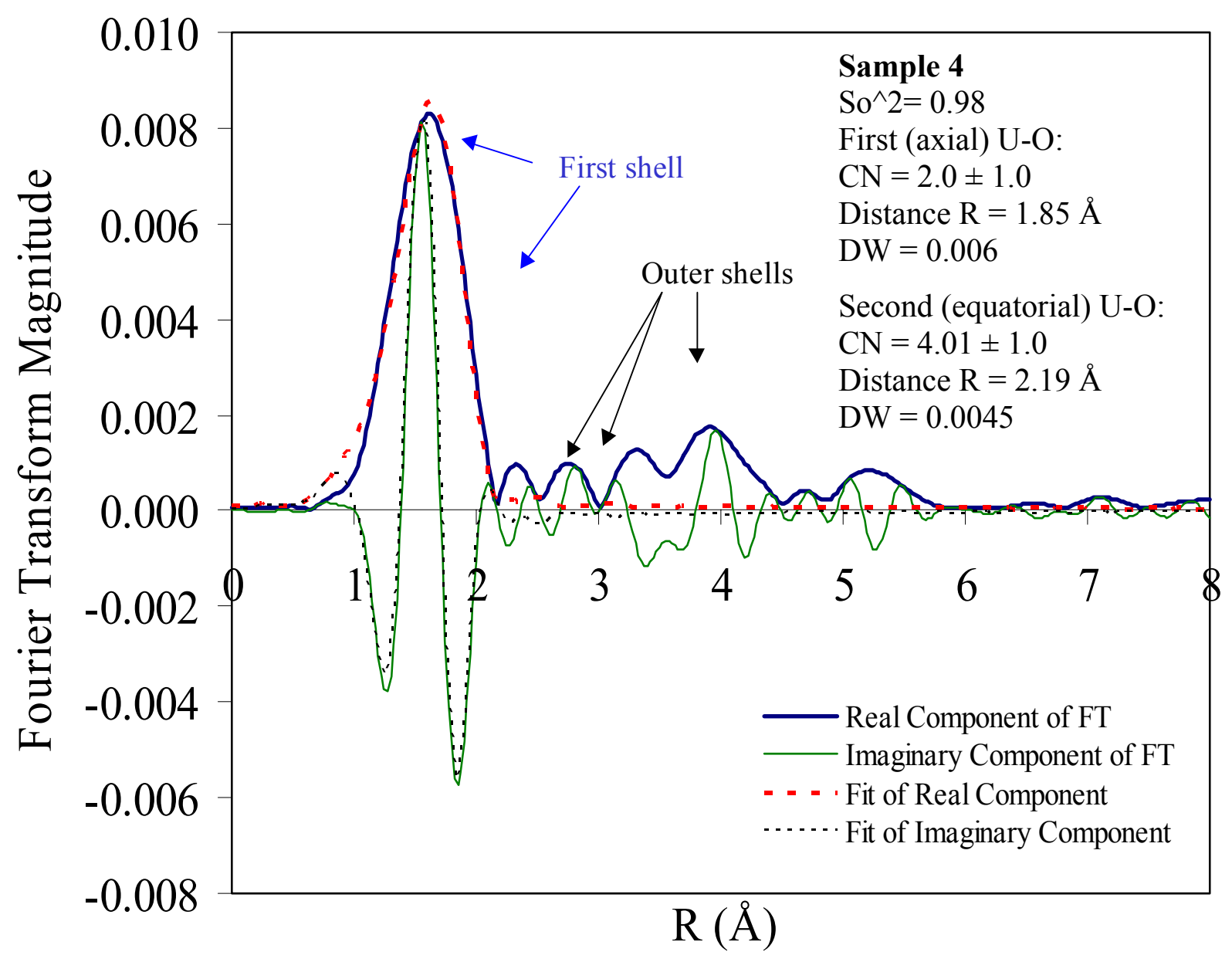

Figure 4-11 FT and first coordination shell fit data for the $2 \mathrm{H}$-Evaporator scale sample \#4uncorrected for phase shift. 
Sample 4: $\mathrm{U} \mathrm{L}_{3}$ Edge EXAFS APS Sector 12BM, Transmission

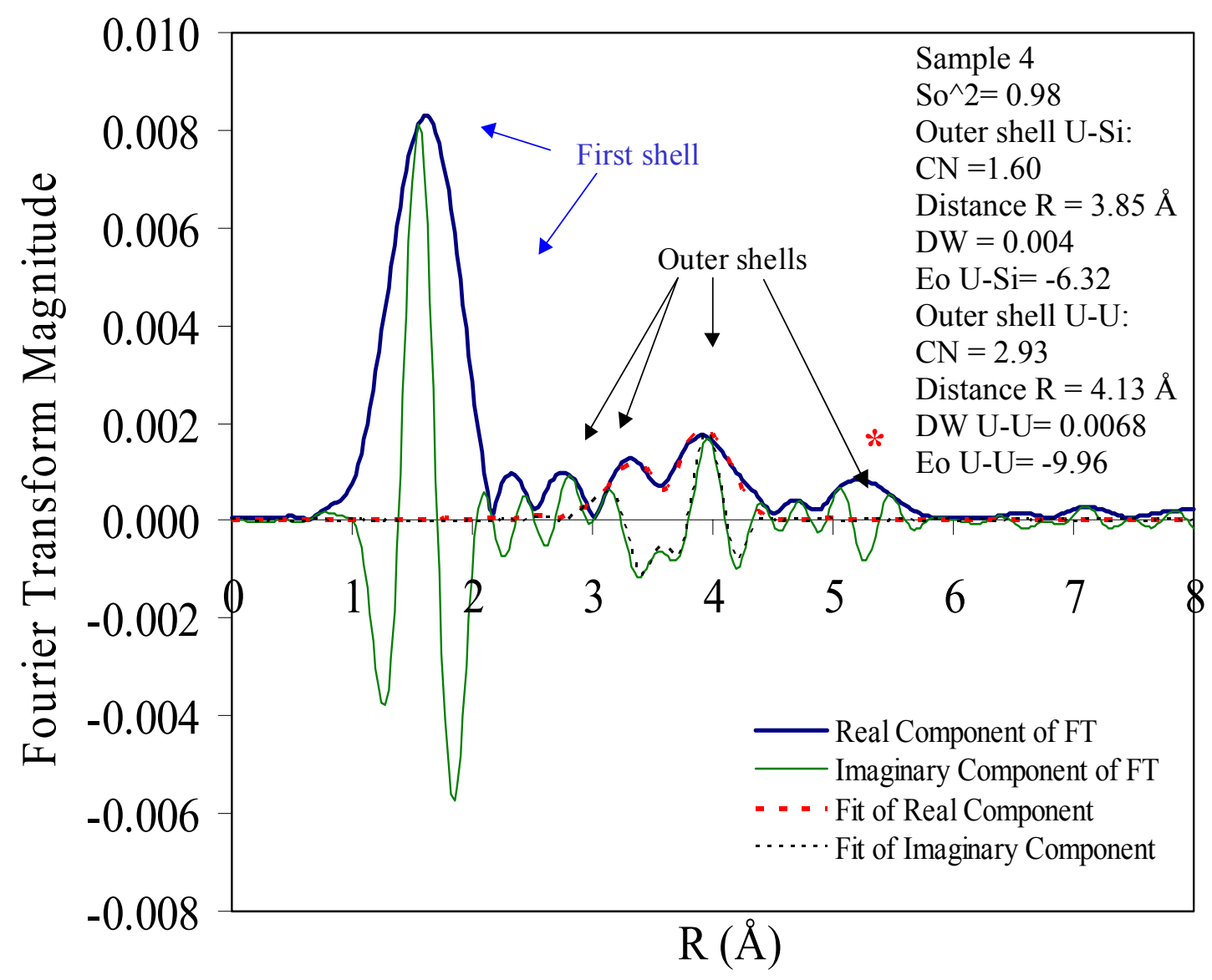

Figure 4-12 FT and higher coordination shell fit data for the 2H-Evaporator scale Sample \#4uncorrected for phase shift. The red asterisk denotes outer shell peak that is consistent with interactions beyond the second and third shells. Fits of this peak in the FT data were not performed. 
Vertex sharing sheet of Si tetrahedra projected along [001]
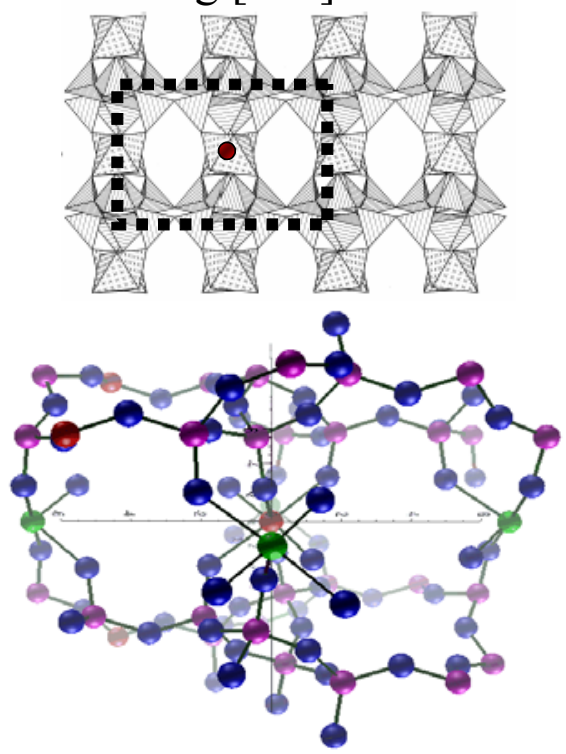

Structure along [100].
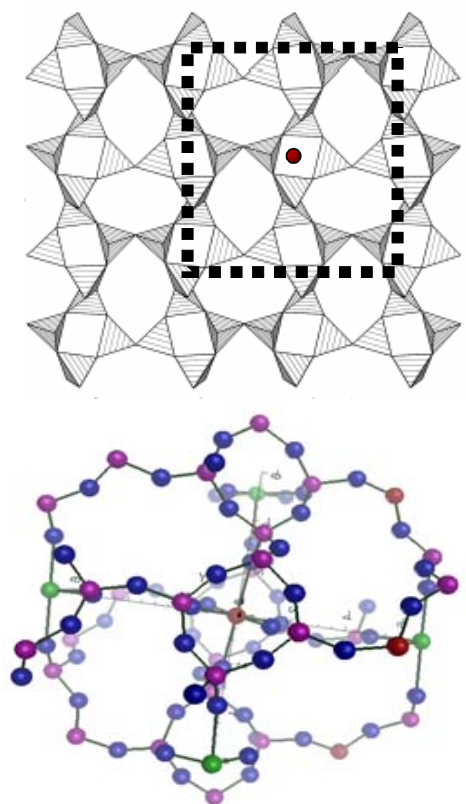

$\mathrm{Na}_{4}\left(\mathrm{UO}_{2}\right)_{2}\left(\mathrm{Si}_{4} \mathrm{O}_{10}\right)_{2}\left(\mathrm{H}_{2} \mathrm{O}\right)_{4}$ : four corner-sharing Si tetrahedra at $3.60 \AA$ and 2 $\mathrm{U}$ at $6.39 \AA$ [Li and Burns (2001) J. Nucl. Mat. 299, 219-226].

Figure 4-13. Atomistic views of the crystal structure of a synthetic uranyl silicate that was made hydrothermally in caustic solution. The $\mathrm{U}$ in this solid has a similar first shell environment to that of the $\mathrm{U}$ in the $2 \mathrm{H}$ Evaporator scale.

\subsubsection{Discussion of the Influence of Silica on Total Solution U, U Accumulation and Solid Phase U Speciation}

According to the results from the XRD and XAFS data analyses, the $\mathrm{U}$ in the $2 \mathrm{H}$-Evaporator scale exists in at least two solid phase forms: a partially-hydrated crystalline (VI) species called clarkeite $\mathrm{Na}_{4}\left(\mathrm{UO}_{2}\right)\left(\mathrm{O}_{2} \mathrm{OH}_{2}\right)_{2(\mathrm{~s})}$ and an amorphous $\mathrm{U}(\mathrm{VI})$-silica phase. Clarkeite has been identified using XRD in studies that have examined the transformation of schoepite and soddyite in high $\mathrm{Na}^{+}$solutions ${ }^{68,69}$ in geologic bodies ${ }^{53,70,71}$ and in studies that simulated the conditions of HLW interactions with sediments underneath Hanford HLW tanks. ${ }^{3}$ Clarkeite has also been identified to form during the caustic precipitation of U-rich solutions. ${ }^{72}$

In summary, the above information indicates that the existence of clarkeite within caustic solutions or evaporated HLW salt solutions that are high in Na and $\mathrm{U}$ is to be anticipated. However, the presence of U-rich silica material in the scale is considerably less expectedmainly because the techniques that have been traditionally used to characterize the scale and other materials in the HLW at SRS are not highly sensitive to amorphous $U$ forms. Therefore, 
our next discussion will include information known about the influence of (colloidal) silica on solution $U$ concentration and $U$ speciation and how it relates to the $2 \mathrm{H}$ Evaporator. We will also provide some discussion that links clarkeite with uranium silicates in geologic systems.

\subsubsection{Interactions of Caustic Solution with Silica}

Work by Traina and researchers with HLW stimulant salt solutions indicate that the addition of high levels of silica (at $0.5 \mathrm{M}$ ) to caustic solutions that are highly saturated in clarkeite can convert clarkeite into an amorphous $\mathrm{U}$ material. ${ }^{3}$ A decrease in solution $\mathrm{pH}$ resulting from the reaction of the silica with $\mathrm{OH}$ ion and a ten-fold increase in solution $\mathrm{U}$ concentration also resulted (from $10^{-5}$ to $10^{-4} \mathrm{M} \mathrm{U}$ ). Hence, the addition of silica is therefore thought to have a destabilizing effect on clarkeite under caustic conditions. These researchers did not characterize the amorphous forms of $U$ in their studies.

\subsubsection{Tank 43 Evaporator Feed Data}

Data on the feed streams introduced to the $2 \mathrm{H}$ Evaporator prior, during and after periods of difficult (i.e., scaling) operation also provide information that supports an enhancement of $U$ solubility by silica. Jantzen and researchers report that the $2 \mathrm{H}$-Evaporator feed was obtained (prior to complete shutdown at the end of 1999) from a region near the measured "zone of turbidity" or "ZOT" within Tank 43 in the year $2000 .^{2}$ The ZOT has high levels of Al, Si, Fe, U, and Mn from unsettled sludge. The ZOT is also likely to contain undissolved frit material, which was sent by DWPF (from the slurry mix evaporator or SME) to Tank 43 between 1996 and 1997. Hence, the ZOT is likely to be a silica rich layer of sol accumulation (i.e., colloidal silica) that does not settle due to the negative charge and hydrophobicity of the silica.

The Jantzen et al. (2000) report, which included a synopsis of data from other reports and recorded data states that the $2 \mathrm{H}$-Evaporator feed pump was positioned at about 100 inches from the bottom of the tank and was located 36 inches above the "ZOT". Considerable deposition of U-rich NAS scale in the $2 \mathrm{H}$ Evaporator was observed after and during the time that waste was taken from near the ZOT. This material near the ZOT (as sampled in 2000) was found to be richer in silica and $U$ than the supernate material near the upper portion of the waste in Tank 43. For example, Si and U levels as high as 4035 and $575 \mathrm{mg} \mathrm{L}^{-1}$ (respectively) in samples taken near the ZOT in contrast to $\mathrm{Si}$ and $\mathrm{U}$ levels of 87 and $18 \mathrm{mg} \mathrm{L}^{-1}$ (respectively) in the dip supernate samples (taken from uppermost portion of Tank 43) after the samples had been allowed to settle and clarify for 6 weeks after collection. Hence, the U concentrations in these samples were at least 10 fold greater near the ZOT than at the tank waste surface. These Tank 43 data indicate that silica, in colloidal form probably has a considerable influence on total (suspended and dissolved) U concentrations in the feed waste.

The characterization work presented in our current report does not directly determine whether the Si was closely associating with $\mathrm{U}$ in the Tank 43 feed material taken from near the ZOT. However, the correlation between high levels of $\mathrm{U}$ with high levels of $\mathrm{Si}$ in the feed material taken from near the ZOT and the presence of $U$ bound to silica in the $2 \mathrm{H}$ scale (based on our XAFS work) support the possibility that silica may enhance the levels of $U$ in the feed material 
and result in $U$ accumulation in the evaporator. Additionally, our characterization focused on only one scale sample that was taken from the innermost portion of scale on the evaporator wall and thus assumed to be freshly deposited material. There may be heterogeneity in U speciation throughout the $2 \mathrm{H}$ Evaporator because of differences in temperature and physical location in the evaporator.

\subsubsection{Accumulation of Silica in the 2H Evaporator}

As previously mentioned based on the SEM studies, $\mathrm{U}$ and Si are also present with $\mathrm{Na}$ and $\mathrm{Al}$. The deposition of silica with alumina is supported by the fact that dissolved alumina has a similar size (although different ionic charge) and to that of dissolved silica and Si and Al can maintain a $\mathrm{CN}$ of 4 or 6 . This makes their association in high $\mathrm{Al}$ and $\mathrm{Si}$ solutions readily favored. Due to its cationic charge, $\mathrm{Na}^{+}$is highly attracted to negatively-charged silica particles in caustic solution - as discussed and reviewed by Iler (1979). ${ }^{73}$ The preference for U-silica accumulation with NAS could also be explained by the unstructured (non-crystalline) nature of the amorphous silica which makes it readily associate with other materials. The evaporation of colloidal silica in forced circulation evaporators is known to results in a layer of hard silica build up. $^{73}$ It is also possible that any entrained U sludge particles or clarkeite solids in the evaporator feed taken from near the ZOT could become associated silica as such a build up. In summary, all of these behaviors could promote the adherence of amorphous silica with NAS in the evaporator.

\subsubsection{Clarkeite Association with Uranyl Silicates in Natural Environments Rich in Na, U and Si}

The presence of clarkeite with U-rich silica in hydrothermal environments is not unprecedented. Natural geologic systems that contain clarkeite are often rich in U, silica and sodium. ${ }^{3}$ The clarkeite in these systems, which is thought to form hydrothermally in brine solutions, also exists with uranyl silicates and quartz, which is a crystalline form of silica. However, the effect of uranyl silicates on clarkeite formation in these geologic systems is not clearly known. It is possible that uranyl silicates may form upon the reaction of clarkeite with dissolved silica. It is also possible that the solid phase $\mathrm{U}$ in the uranyl silicates may become converted to clarkeite, with the reaction resulting in the release of silica. These natural systems do not truly compare with evaporator. For example, the longer (geologic) timescales of reaction and the lower $\mathrm{pH}$ values associated with these subsurface geologic reactions do not compare with that of the evaporator. Radiation can induce the conversion of crystalline $U$ silicate solids to amorphous $U$ silicate solids, which may be overlooked in XRD studies. ${ }^{74}$ However, the amorphous U phases were not characterized in this system.

\subsubsection{Summary of Interactions that Relate to the Deposition and Accumulation of $U$ and Silica in Scale}

In summary, several conditions and observations support an assumption that the high level of (saturated) silica favors the deposition of U-rich scale in the $2 \mathrm{H}$ Evaporator: 
1) High levels of colloidal silica (i.e., highly saturated $\mathrm{Si}$ ) and $\mathrm{U}$ were in present the incoming feed material obtained from the ZOT [as noted by Jantzen et al. (2000)], ${ }^{2}$

2) There is a correlation between high total silica being sent to Tank 43 and the deposition of U-rich scale in the evaporator [as noted by Jantzen et al. (2000)],

3) Polymeric (precipitated) $U$ is closely associated with silica in the freshly-deposited scale (this report),

4) SEM imaging data combined with energy dispersive spectrometry suggest that $\mathrm{Na}, \mathrm{Si}$, and $\mathrm{Al}$ (presumably as NAS) are often associated with solid phase $\mathrm{U}$ in the evaporator scale, indicating that U-rich silica material (as identified by XAFS) has an affinity for the NAS (this report),

5) No recorded deposition of scale other than $\mathrm{NaNO}_{3}$ (which was easily removed by washing with flush water) was observed in the $2 \mathrm{H}$ Evaporator during the 40 -year period prior to the time that the evaporator was feed high levels of silica and $\mathrm{Al}$ and given undissolved (SME) frit carryover from DWPF operations [as noted in Jantzen et al. $(2000)],{ }^{2}$

6) Clarkeite and crystalline uranium silicates are known to co-exist in $\mathrm{Na}, \mathrm{Si}$ and $\mathrm{U}$ rich solutions in nature (work by Finch and Ewing) ${ }^{53}$ and

7) The addition of high levels of silica to caustic results in a destabilization of clarkeite and possible conversion to an amorphous material (Traina and co-workers). ${ }^{3}$

\subsection{CONCLUSIONS}

The results indicate that $\mathrm{U}$ is present as clarkeite as well as another unidentified most likely amorphous uranyl silicate phase. Crystallographic data for U solids that form at high temperature under caustic, high $\mathrm{Na}^{+}$and high radiation conditions are lacking. Additionally, we do not have characterization data for the Tank 43 feed material taken near the ZOT. Such information would increase our understanding of $\mathrm{U}$ deposition in the $2 \mathrm{H}$ Evaporator.

Our XAFS data do not report clarkeite to be the dominant phase although we anticipated it to be most likely, based on the initial results of our XRD analyses. The XRD data for our archived sample from the evaporator wall do not completely resemble that acquire previously with another $2 \mathrm{H}$-Evaporator scale sample from the evaporator pot. These results suggest that there is some heterogeneity amongst the deposits in the scale. Our report focuses on the characterization of a single $2 \mathrm{H}$-Evaporator scale sample. We cannot determine what distribution of $\mathrm{U}$ is similar to that of our single archived sample. However, we believe that this sample, because of its location being from the innermost portion of the evaporator is a recently deposited material.

It could be expected that the presence of undissolved frit and high levels of colloidal silica (from the DWPF recycle) in the Tank 43 feed could promote interactions of $U$ with silica in the $2 \mathrm{H}$ 
Evaporator. Amorphous silica probably plays an important role on $\mathrm{U}$ accumulation in the $2 \mathrm{H}-$ Evaporator because of its likely presence in the evaporator feed and its destabilizing effect on clarkeite in clarkeite-saturated caustic solutions. It may be that this type of U-silica material becomes accumulated in the evaporator, providing there is a host surface, such as sodalite or cancrinite present. With time and evaporator cycling, this U-rich silica material may eventually convert to clarkeite as observed in the more aged $2 \mathrm{H}$ scale material that was first described by Wilmarth et al. (2001) and later revisited (i.e., the XRD data) in this report.

\subsection{QUALITY ASSURANCE}

The following documents govern the work reported in this document.

- M. C. Duff, D. B. Hunter and B. Wilmarth, "Task Technical and Quality Assurance Plan for XAFS Analyses on Uranium Scale Solids from the 2H Evaporator,” WSRC-RP-2003-00271, March 4, 2003.

- Notebook WSRC-NB-2001-00052 (M. C. Duff) contains the experimental XAFS data obtained from this work.

\subsection{ACKNOWLEDGEMENTS}

The authors acknowledge Drs. L. Soderholm, S. Skanthakumar, and M. Antonio, who are members of the Actinide, which is primarily supported by DOE Office of Basic Energy Sciences Facility ( at Argonne National Laboratory). They graciously facilitated the packaging of our samples as they transitioned from Argonne's Chemistry Building to the Advanced Photon Source. Members of the Actinide Facility also donated their experimental research time at BESSRC 12-BM beamline at the APS to assist us in conducting our XAFS studies. We also thank B. Glagola (APS) and Dr. J. Linton (APS) for their support for the approval and set-up of these XAFS studies at the APS facility. The authors thank S. Robertson (WSRC), E. Freed (WSRC), D. C. Bumgardner (WSRC), D. J. Martin (WSRC), S. Reboul (WSRC), and L. Coffey (DOE) for their assistance, support and ideas. Mrs. B. Croy, V. Dukes and J. T. Mills (all of SRTC) provided excellent laboratory assistance with sample preparation. C. Diprete and D. Diprete performed the radiometric analyses of the samples and M. Malek, P. Waller, and B. Boyce (all of SRTC) performed the ICP-MS analyses. Mrs. C. Pierce (WSRC) and E. Johnson (WSRC) provided excellent health physics support in the laboratory. 
WSRC-TR-2004-00016, REVISION 0

\subsection{REFERENCES}

${ }^{1}$ Wilmarth, W. R., Thompson, M. C., Martino, C. J., Dukes, V. H., Mills, J. T., Boley, C. and Lewis, B. L. (2001). "Nitric Acid Cleaning of a Sodalite - Sodium Diuranate Scale in High Level Waste Evaporators. WSRC-MS-2001-00715.

${ }^{2}$ Jantzen, C. M., Laurinat, J. E. and Brown, K. G. (2000). "Thermodynamic modeling of the SRS Evaporators: Part 1. The 2H and 2F Systems (U).”WSRC-TR-2000-00293, April 4, 2002.

${ }^{3}$ Traina, S. J. et al. (2002). "Immobilization of Radionuclides in the Hanford Vadose Zone by Incorporation in Solid Phases," Project DE-FG07-99ER15010. Environmental Management Science Program (EMSP) Annual Report 2002.

${ }^{4}$ Stumm, W. (1992). Chemistry of the Solid-Water Interface: Processes at the Mineral-Water and Particle-Water Interface in Natural Systems. Wiley-Interscience, NY.

${ }^{5}$ McBride, M. B. (1994). Environmental Chemistry of Soils. Oxford Press, NY.

${ }^{6}$ Due to the small nature of nanoparticles, they often have more atoms at the solid-water interface than inside the solid. The use of spectroscopic techniques to elucidate the exact location of sorbing metals in such solids may potentially result in an inability to determine whether the metal is in an interlayer or vacancy site.

${ }^{7}$ Sorption reversibility is tested by leaching the metal loaded solid with a target metal-free solution that has the same properties (i.e. ionic strength, background electrolytes, $\mathrm{pH}$ etc...) and measuring the leachate solution to determine whether any target metal is released. Specifically adsorbed species are typically not leached with lower ionic strength solutions and specific adsorption processes are not a function ionic strength (assuming the electrolytes do not interact with the sorbed species via complexation etc.). Outersphere species can be readily removed with solutions of low ionic strength or solutions that contain high concentrations of a cation that has a higher affinity for the surface than the outer-sphere species. Therefore, outer-sphere sorption is viewed as reversible and a function of ionic strength.

${ }^{8}$ Specific adsorption is typically a function of surface charge properties. When a participating surface has a charge that varies with solution $\mathrm{pH}$, specific adsorption exhibits $\mathrm{pH}$-dependent behavior. For example, a surface that is highly protonated (at low $\mathrm{pH}$ ) will have more affinity for negatively-charged species. As the $\mathrm{pH}$ decreases, the surface charge of $\mathrm{pH}$-dependent charged surface becomes more negative and the uptake of positively charged species is favored. Therefore, the surface of metal oxides for example specifically adsorbs more positively charged species as the solution $\mathrm{pH}$ increases. However, this behavior is generalized. As the solution $\mathrm{pH}$ increases sorbing species undergoes a change in speciation-such as hydrolysis. In this case, the amount of specific adsorption becomes a function of solution speciation. Ion exchange resins that sorb free ions of actinides (e.g., the non-hydrolyzed $\mathrm{Pu}^{4+}$ species) at high $\mathrm{H}^{+}$ concentrations (i.e., low $\mathrm{pH}$ ) will release sorbed $\mathrm{Pu}^{4+}$ species when the solution $\mathrm{pH}$ is raised-due to the hydrolysis of the sorbed $\mathrm{Pu}^{4+}\left(\right.$ e.g., $\left.\mathrm{Pu}(\mathrm{OH})_{3}{ }^{+}, \mathrm{Pu}(\mathrm{OH})_{2}{ }^{2+}\right)$. The hydrolysis species have a lower overall charge and their size (as an ion group) is larger than the free ion-making them have a lower affinity for the surface. Other processes [particularly for U(VI)] that can influence sorption are metal complexation with ligands (i.e., with carbonate ion) or in the case of anions, protonation (e.g., $\mathrm{PO}_{4}{ }^{3-}+\mathrm{H}^{+} \rightarrow \mathrm{HPO}_{4}{ }^{2-}$ ). Specific adsorption processes are a function of many variables. 
${ }^{9}$ Olguin, M. T., Duque, J., Pomés, R., Villafuerte-Castrejón, M. E., Sansores, L. E., Bosch, P. and Bulbulian, S. (1997). Characterization of $\mathrm{UO}_{2}{ }^{2+}$-exchanged Y zeolite. J. Radio. Anal. Nucl. Chem. 222, 235-237.

${ }^{10}$ No U-aluminate solid phases have been documented. If these phases form, other U phases, such as the oxides, hydroxides and silicates of $U$ are more likely dominate the speciation of solid phase $U$ under evaporator and salt solution conditions.

${ }^{11}$ Li, Y. and Burns, P. C. (2001). The structures of two sodium uranyl compounds relevant to nuclear waste disposal. J. Nucl. Mater. 299, 219-226.

${ }^{12}$ Shannon, R. D. (1976). Revised effective ionic radii and systemic studies of interatomic distances in halides and chalcogenides. Acta Cryst. A32, 751-767.

${ }^{13}$ Farges, F., Ponader, C. W., Calas, G. and Brown, G. E., Jr. (1992). Structural environments of incompatible elements in silicate glass/melt systems: II. $\mathrm{U}^{\mathrm{IV}}, \mathrm{U}^{\mathrm{V}}$, and $\mathrm{U}^{\mathrm{VI}}$. Geochim. Cosmochim. Acta. 56, 4205-4220.

${ }^{14}$ Griffiths, T. R. and Volkovich, V. A. (1999). A review of the high temperature oxidation of uranium oxides in molten salts and in the solids state to form alkali metal uranates, and their composition properties. J. Nucl. Mater. 274, 229-251.

${ }^{15}$ A discussion of the uranate structures and misclassifications is an important topic but such discussion is not warranted in this report given the results that will be discussed.

${ }^{16}$ Hobbs, D. T., Bronikowski, M. G., Edwards, T. B. and Pulmano, R. L. (1999). "Final Report on Phase III Testing of Monosodium Titanate Adsorption,” WSRC-TR-99-00134, May 28, 1999.

${ }^{17}$ Duff, M. C., Hobbs, D. T. and Fink, S. D. (2002). "Permanganate Treatment Optimization Studies for Strontium and Actinide Removal from High Level Waste Simulants," WSRC-TR-2002-0027, Jan. 14, 2002.

${ }^{18}$ Crespo, M. T., Gascon, J. L. and Acena, M. L. (1993). Techniques and analytical methods in the determination of uranium, thorium, plutonium, americium and radium by adsorption on manganese dioxide. Sci. Tot. Environ. 130, 383-391.

${ }^{19}$ Duff, M. C., Hunter, D. B., Hobbs, D. T., Jurgensen, A. and Fink, S. D. (2002). "Characterization of Sorbed Plutonium, Neptunium, Strontium on Manganese Solids from Permanganate Reduction." WSRCTR-2002-00366, Rev. 0, Sept. 19, 2002.

${ }^{20}$ Clark, D. L., Conradson, S. A., Donohoe, R. J., Keogh, D. W., Morris, D. E., Palmer, P. D., Rogers, R. D. and Tait, C. D. (1999). Chemical speciation of the uranyl ion under highly alkaline conditions, synthesis, structures and oxo ligand exchange dynamics. Inorg. Chem. 38, 1456-1466.

${ }^{21}$ Hsi, C-K. D. and Langmuir, D. (1985). Adsorption of uranyl onto ferric oxyhydroxides: Applications of the surface complexation site-binding model. Geochim. Cosmochim. Acta 49, 1931-1941.

${ }^{22}$ Duff, M. C. and Amrhein, C. (1996). Uranium(VI) adsorption on goethite and soil in carbonate solutions. Soil Sci. Soc. Amer. J. 743, 1393-1400. 
${ }^{23}$ Aky1l, S., Aslani, M. A. A., Ǒlmez, Ş. and Eral, M. (1996). Kinetic studies of uranium(VI) adsorption on a composit ion exchanger. J. Radioanal. Nucl. Chem. Lett. 213, 441-450.

${ }^{24}$ El Aamrani, F. Z., Duro, L., De Pablo, J. and Bruno, J. (2002). Experimental study and modeling of the sorption of uranium(VI) onto olivine rock. Appl. Geochem. 17, 399-408.

${ }^{25}$ Aky1l, S., Aslani, M. A. A. and Aytaş, Ş. (1998). Distribution of uranium on zeolite X and investigation of thermodynamic parameters for this system. J. Alloys Cpds 271/273, 769-773.

${ }^{26}$ Prikryl, J. D., Jain, A., Turner, D. R. and Pabalan, R. T. (2001). Uranium(VI) sorption behavior on silicate mineral mixtures. J. Contam. Hydrol. 47, 241-253.

${ }^{27}$ Reich, T. et al. (1996). Characterization of hydrous uranyl silicate by EXAFS. Radiochim. Acta 74, 219-223.

${ }^{28}$ Duff, M. C., Coughlin, J. U. and Hunter, D. B. (2002). Uranium co-precipitation with Fe oxide minerals. Geochim. Cosmochim. Acta 66, 3533-3547.

${ }^{29}$ Bargar, J. R., Reitmeyer, R., Lehnart, J. J. and Davis, J. A. (2000). Characterization of U(VI)-carbonato ternary complexes on hematite: EXAFS and electrophoretic mobility measurements. Geochim.

Cosmochim. Acta. 64, 2737-2749.

${ }^{30}$ Koningsberger, D. C. and Prins, R. (1988). X-ray Absorption: Techniques of EXAFS, SEXAFS and $X A N E S$, Wiley, New York.

${ }^{31}$ Stern, E. A. (1974). Theory of extended X-ray absorption fine structure. Phys. Rev. B10, 3027-3037.

${ }^{32}$ Moyes, L. N., Parkman, R. H., Charnock, J. M., Vaughan, D. J., Livens, F. R., Hughes, C. R. and Braithwaite, A. (2000). Uranium uptake from aqueous solution by interaction with goethite, lepidocrocite, muscovite, and mackinawite: An X-ray absorption spectroscopy study. Environ. Sci. Technol. 34, 10621068.

${ }^{33}$ Hudson, E. A., Terminello, L. J., Viani, B. E., Denecke, M., Reich, T., Allen, P. G., Bucher, J. J., Shuh, D. K. and Edelstein, N. M. (1999). The structure of $\mathrm{U}^{6+}$ sorption complexes on vermiculite and hydrobiotite. Clays Clay Min. 47, 439-457.

${ }^{34}$ Chisholm-Brause, C., Conradson, S. D., Buscher, C. T., Eller, P. G. and Morris, D. E. (1994). Speciation of uranyl sorbed at multiple binding sites on montmorillionite. Geochim. Cosmochim. Acta. $\mathbf{5 8}, 3625-3631$.

${ }^{35}$ Waite, T. D., Davis, J. A., Payne, T. E., Waychunas, G. A. and Xu, N. (1994). Uranium adsorption to ferrihydrate: Application of a surface complexation model. Geochim. Cosmochim. Acta. 58, 5465-5478.

${ }^{36}$ Wersin, P., Hochella, M. F., Persson, J., Redden, G., Leckie, J. O. and Harris, D. W. (1994). Interaction between aqueous uranium(VI) and sulfide minerals: Spectroscopic evidence for sorption and reduction. Geochim. Cosmochim. Acta 58, 2829-2843.

${ }^{37}$ Bargar, J. R., Reitmeyer, R. and Davis, J. A. (1999). Spectroscopic confirmation of uranium(VI)carbonato adsorption complexes on hematite. Env. Sci. Technol. 33, 2481-2484. 
${ }^{38}$ Sylwester, E. R., Hudson, E. A. and Allen, P. G. (2000). The structure of uranium(VI) sorption complexes on silica, alumina and montmorillonite. Geochim. Cosmochim. Acta. 64, 2431-2438.

${ }^{39}$ Lieser, K. H., Quandtklenk, S. and Thybusch, B. (1992). Sorption of uranyl ions on hydrous silicon dioxide. Radiochim. Acta 57, 45-50.

${ }^{40}$ Allen, P. G., et al., (1996). Determinations of uranium structures by EXAFS: Schoepite and other U(VI) oxide precipitates. Radiochim. Acta 75, 47-53.

${ }^{41}$ Thompson, H. A., Brown, G. E. and Parks, G. A. (1997). XAFS spectroscopic study of uranyl coordination in solids and aqueous solution. Amer. Mineral. 82, 483-496.

${ }^{42}$ Allard, T., Ildefonse, P., Beaucaire, C. and Calas, G. (1999). Structural chemistry of uranium associated with $\mathrm{Si}, \mathrm{Al}, \mathrm{Fe}$ gels in a granitic uranium mine. Chem. Geol. 158, 81-103.

${ }^{43}$ Sturchio, N. C., Antonio, M. R., Soderholm, L., Sutton, S. R. and Brannon, J. C. (1998). Tetravalent uranium in calcite. Science 281, 971-973.

${ }^{44}$ Reeder, R. J., Nugent, M., Tait, C. D. and Morris, D. E. (2000). Uranyl incorporation into calcite and aragonite: XAFS and luminescence studies. Environ. Sci Technol. 34, 638-644.

${ }^{45}$ Smectites are phylloaluminosilicates mineral consisting of layers of aluminum octahedra and silicon tetrahedra that contain metals (such as $\mathrm{Fe}^{2+, 3+} \mathrm{Mn}^{2+}$ and $\mathrm{Mg}^{2+}$ ) within the structural vacancies. Fixed charge sites on aluminosilicate clays do not exhibit $\mathrm{pH}$-dependent surface charge behavior. These fixed charge sites typically sorb solution ions via an outer sphere/electrostatic mechanism. The fixed charge of the sites comes from an imbalance in internal structural charge due to the substitution of metal ions with a different charge than that which would normally fulfill charge balance in the clay structure (specifically, $\mathrm{Al}^{3+}$ and $\mathrm{Si}^{4+}$ ). On the edges of these structural layers are broken edge sites, which exhibit $\mathrm{pH}$-dependent charge behavior due to their propensity to protonation and deprotonation. It is at these sites that specific adsorption of metals such as uranyl can occur.

${ }^{46}$ Zachara, J. M. and McKinley, J. P. (1993). Influence of hydrolysis on the sorption of metal cations by smectites: Importance of edge coordination reactions. Aquatic Sciences. 55, 250-261.

${ }^{47}$ Azenha, M. E. D. G., da Graça Miguel, M., Formosinho, S. J. and Burrows, H. D. (2001). The characterization by luminescence spectroscopy of uranium(VI) incorporated into zeolites and aluminas. $J$. Molec. Structure 563-564, 439-442.

${ }^{48}$ Duff, M. C., Hunter, D. B. and L. N. Oji, "Characterization of Uranium Solids Precipitated with Aluminosilicates,” WSRC-TR-2002-00527, Rev. 0.0, November 24, 2002.

${ }^{49}$ Burns, P. C. (1999). The Crystal Chemistry of Uranium. In: Uranium: Mineralogy, Geochemistry and the Environment. Reviews in Mineralogy 38, pp. 23-90, Mineral. Soc. Amer.

${ }^{50}$ Burns, P. C., Ewing, R. C. and Hawthorn, F. C. (1997). The crystal chemistry of hexavalent uranium: Polyhedral geometries, bond-valence parameters, and polymerization of polyhedra. Can. Mineral. 35, 1551-1570. 
${ }^{51}$ Duff, M. C., Hunter, D. B., Barnes, M. J. and Fink, S. D. (2002). "Characterization of uranium and mercury speciation in high level waste tank 8F and 11H sludge," WSRC-TR-2001-00428, Rev. 0.

52 Oji, L. N. (2004). "Conditions Conducive to Forming Crystalline Uranyl Silicates in SRS Evaporators." WSRC-TR-2003-00533, Rev. 0.

${ }^{53}$ Finch, R. F. and Ewing, R. C. (1997). Clarkeite: New chemical and structural data. Amer. Mineralogist, 82, 607-619.

${ }^{54}$ Beno, M. A., Engbretson, M., Jennings, G., Knapp, G. S., Linton, J., Kurtz, C., Rűtt, U. and Monaton, P. A. (2001). BESSRC-CAT bending magnet beamline at the advanced photon source. Nucl. Instrum. Methods Phys. Res. A, 467-468, 699-702.

${ }^{55}$ Teo, B. K. (1986). EXAFS: Basic Principles and Data Analysis. Inorganic Chemistry Concepts, Vol. 9 , Springer-Verlag. Berlin.

${ }^{56}$ Ressler, T. (1999). WinXAS. A program for X-ray absorption spectroscopy data analysis under MS Windows. J. Synchr. Rad. 5, 118-122.

${ }^{57}$ Newville, M., Livins, P., Yacoby, Y., Rehr, J. J. and Stern, E. A. (1993). Near-edge X-ray-absorption fine-structure of $\mathrm{Pb}$ - A comparison of theory and experiment. Phys. Rev. B-Cond. Matter, 47, 1412614131.

${ }^{58}$ Sayers, D. E. and Bunker, B. A. (1988). In X-ray Absorption: Techniques of EXAFS, SEXAFS and XANES. Koningsberger, D. C. and Prins, R. (eds). Wiley, New York, Chap. 6.

${ }^{59}$ FEFF is a software package that was generated by researchers at the Univ. of Washington with DOE funding support. Access and use of this software is free within the DOE complex.

${ }^{60}$ Mustre de Leon, J., Rehr, J. J., Zabinsky, S. I. and Albers, R. C. (1991). Ab initio curved-wave x-rayabsorption fine structure, Phys. Rev. B44, 4146.

${ }^{61}$ Rehr, J. J. and Albers, R. C. (1990). Scattering-matrix formulation of curved-wave multiple-scattering theory: Application to x-ray-absorption fine structure. Phys. Rev. B41, 8139.

${ }^{62}$ Rehr, J. J., Mustre de Leon, J., Zabinsky, S. I. and Albers, R. C. (1991). Theoretical X-ray absorption fine structure standards. J. Am. Chem. Soc. 113, 5135.

${ }^{63}$ Rehr, J. J., Zabinsky, S. I. and Albers, R. C. (1992). High-order multiple scattering calculations of xray-absorption fine structure. Phys. Rev. Let. 69, 3397.

${ }^{64}$ Stern, E. A., Newville, M., Ravel, B., Yacoby, Y. and Haskel, D. (1995). The UWAFS analysis package - Philosophy and details. Physica B. 208-209, 117-120.

${ }^{65}$ Wilmarth, W. R., Coleman, C. J., Hart, J. C. and Boyce, W. T. (2000). "Characterization of Sampled from the 242-16H Evaporator Wall," WSRC-TR-2000-00089.

${ }^{66}$ Cordfunke, E. H. P. and Loopstra, B. O. (1971). Sodium uranates: Preparation and thermochemical properties. J. Inorg. Nucl. Chem. 33, 2427-2436. 
${ }^{67}$ There is more than one type of sodium uranate known and there are several reported structurally distinct sodium diuranate solids. Prior to the emergence of diffraction data for clarkeite, the sodium diuranate that had been identified by XRD to form in the SRS HLW tank farm and simulants is that are described by Cordfunke and Loopstra (1971).

${ }^{68}$ Giammar, D. E. and Hering, J. G. (2002). Equilibrium and kinetic aspects of soddyite dissolution and secondary phase precipitation in aqueous suspension. Geochim. Cosmochim. Acta 66, 3235-3245.

${ }^{69}$ Giammar, D. E. and Hering, J. G. (2004). Influence of dissolved sodium and cesium on uranyl oxide hydrate solubility. Environ. Sci. Technol. 38, 171-179.

${ }^{70}$ Frondel, C. and Meyrowitz, R. (1956). Studies of uranium minerals (XIX): Rutherfordine, diderichite, and clarkeite. Amer. Mineralogist, 41, 127-133.

${ }^{71}$ El Hazek, N., El Kammar, A., Mahdy, M. and Amer, T. (1995). Contribution to geochemistry and CuU mineralogy of carboniferous sedimentary rocks, west central Sinai. Sedimentological Society of Egypt. Vol. 3 Abstracts.

${ }^{72}$ Visser, A. E., Rudisill, T. S. and Bronikowski, M. G. (2003). "Investigation of Plutonium and Uranium Precipitation Behavior with Gadolinium as a Neutron Poison,” WSRC-TR-2003-000193. Rev. 0.

${ }^{73}$ Iler, R. K. (1979). The Chemistry of Silica: Solubility, Polymerization, Colloid and Surface Properties and Biochemistry. John Wiley, and Sons, New York., NY.

${ }^{74}$ Utsunomiya, S., Wang, L-M., Douglas, M., Clark, S. B. and Ewing, R. C. (2003). The effect of ionizing radiation on uranophane. Amer. Mineral. 88, 159-166. 